Decomposition of Energy Consumption and Energy Intensity in Indian Manufacturing Industries

Binay Kumar Ray and B.Sudhakara Reddy

Indira Gandhi Institute of Development Research, Mumbai December 2007 


\title{
Decomposition of Energy Consumption and Energy Intensity in Indian Manufacturing Industries
}

\author{
Binay Kumar Ray and B.Sudhakara Reddy \\ Indira Gandhi Institute of Development Research (IGIDR) \\ General Arun Kumar Vaidya Marg \\ Goregaon (E), Mumbai- 400065, INDIA \\ Email (corresponding author): sreddy@igidr.ac.in
}

\begin{abstract}
Of the total final energy consumption in India, the industrial sector accounts for about 37 percent, of which the manufacturing sector consumes about 66 percent (2004-2005 figures) with chemicals and petrochemicals, iron and steel, pulp and paper and cement industries being the largest energy users. In the recent past, energy intensity in the manufacturing sector has been decreasing. This decline is mainly due to fuel substitution away from coal in some of the sectors, most notably cement. While industrial production in developed countries stabilizes and declines, the industrial output in the developing world continues to expand owing to rising populations and catching up on economic growth. This can result in higher energy use - energy provided primarily by the combustion of fossil fuels - and thereby higher carbon-dioxide $\left(\mathrm{CO}_{2}\right)$ emissions. Using the decomposition analysis we show that most of the intensity reductions are driven purely by structural effect rather than energy intensity.
\end{abstract}




\title{
Decomposition of Energy Consumption and Energy Intensity in Indian Manufacturing Industries
}

\author{
Binay Kumar Ray and B.Sudhakara Reddy
}

\section{INTRODUCTION}

The oil crisis of 1970s has jolted the globe and led policymakers to bring the energy question back on table. Global discussion gained further momentum following the Kyoto conference. Since then, a quantitative assessment of factors that contributes to changes in energy consumption has become important. It helps in understanding the past trends in energy use for measuring the effectiveness of energy-related policies, to forecast future energy demand and carbon emissions and to improve the overall efficiency of energy use (Park , 1992 and Farla et al. 1996) . The three main factors that play a significant role in affecting the level of energy consumption in an economy are: the level of overall activity or production, the composition or structure of the economy, and the output or activity per unit of energy consumed (Nooji et al, 2003). Since the industrial sector is a major consumer of energy, improvements in its service/ activity/output are important to enhance productivity and reduce environmental impacts. In this regard, energy intensity indicators play a significant role to study the trend and the changes in the activity/output levels. In India, the industrial sector contributes about 30 percent of gross domestic product (GDP) (manufacturing accounting for 80 percent) and consumes about 35 percent of total energy. In the industrial sector, energy intensity, i.e., energy/power costs per value added, and energy efficiency, i.e., energy consumption per unit of goods produced is the indicator of energy-intensity levels. Total energy consumed in a sector, for example, is a product of energy intensity per unit of output and the total amount of output provided. Energy intensity is thought to be inversely related to efficiency, the less energy required to produce a unit of output or service, the greater the efficiency. A logical conclusion, then, is that declining energy intensities over time may be indicators of improvements in energy efficiencies. The $\mathrm{CO}_{2}$ emission is another hot issue in today's world due to change in the concentration of $\mathrm{CO}_{2}$ in the atmosphere where the concentration of $\mathrm{CO}_{2}$ is rising every year at the rate of 0.5 percentage per year and the main effect of anthropogenic emission of $\mathrm{CO}_{2}$ comes from combustion of fossil fuel for energy. The World Bank points out that $\mathrm{CO}_{2}$ emission level of 26.9 billion tones of $\mathrm{CO}_{2}$ in the year 2004 is a significant increase from 21.2 in 1990 showing an annual increase of 1.7 percent 
(Little Green Data Book 2007). In India CO2 emissions increased by 57\% from 1990 (1.06 billion tonnes) to 1998, accounting for 4.4 percent of world's share. Similarly for China an increase of 73\% in $\mathrm{CO}_{2}$ emissions between 1990 and 2003. Even though India and China are on fast growth path as for as $\mathrm{CO}_{2}$ emissions are concerned both the countries are still very low on per capita terms. On an average, India and China emit 6 and 16\% of the emissions of USA and are very low compared to the developed world (Little Green Data Book 2007). The per capita emission levels for India and China increased from 0.8 to 1.2 and 2.1 to 3.2, respectively between 1990 and 2003 (World Bank, 2003).

In many cases, technologies and processes use a lot more energy than the theoretical minimum energy requirement. Major energy-intensive industries in India, are: iron and steel, chemicals, textiles, aluminum, fertilizers, cement, paper and non-ferrous metals. Within the industrial sector, the main end-uses of energy are: motors (47 percent), electrical heating/ melting (28 percent), air compression (10 percent) and lighting (4 percent). Industrial energy intensity is affected by a number of factors: technology design, age and sophistication of equip-ment, mechanical and chemical constraints, and external factors such as operating environment, maintenance and repair practices. These factors can be grouped under two broad groups, structural and economic change. The question that arises then is how these two changes have affected energy intensity in India. To date, no studies have examined this dimension of energy use in India thus leaving a gap in India’s energy literature.

The decomposition of the overall change into these two categories can provide policymakers with the information needed to design appropriate strategies for reduction in energy use while helping to mitigate the environmental impacts of industrial energy use. In the light of this, this study examines the usefulness of energy-intensity indicators as policy tools in the context of issues related to the efficiency of India's industrial sector. The challenge is to reduce global GHG emissions without affecting the required energy services.

\section{ENERGY INTENSITY AND DECOMPOSITION STUDIES: LITERATURE OVERVIEW}

One of the index methods available to compare and decompose energy consumption and energy intensity is the Divisia index model (Difference and ratio). This study utilizes an existing methodology, total differentiation model, to calculate the changes. Choi and Ang 
(2003) have proved that there is symmetry between "ratios’ method" and "differences method" of decomposition analysis. Thus, with proper choice of formula ratios and differences, which constitute decomposition, these two alternatives can be used almost interchangeably. Reddy (1998) used this approach to decompose Fiji's energy intensity change into these two categories. Jing et al. (1990), Boyd et al.(1988), Park et al. (1992) and Lin and Chang (1996) have also applied the decomposition method. Rose and Caster (1996) have summarized various types of decomposition methods According to De Bruyn (2000), if the input and output data were not available, then one can use some index numbers for decomposition. In all these studies, residual term is considered as zero. Ang and Lee (1994) observe that a major part of the observed changes in the energy consumption being decomposed is left unexplained. This means that the residuals give large estimation error in the decomposition analysis. Park (1992) has shown that the structural effect, calculated as a residual by the RRS (developed by Reitler, Rudolph and Schaefer) raises a number of logical questions. First, the RRS method takes the mean value of the variable in question between the base period and the end period. Like the net effect, structural change on industrial energy consumption between any two periods can be isolated by measuring a change in energy consumption associated with a change in the industrial composition during the period. This can be done while holding all other variables of the base period constant at their initial values (energy intensities of the individual industry branches and total industrial output in this case). Similarly, separate industrial output effect can be measured by allowing the industrial output to change, while the values of other variables are kept constant at their initial values. In short, RRS method may relate more closely to this ceteris paribus change concept. Second, and more importantly, the RRS method failed to introduce structural change explicitly as a variable in the equation. As a result, the RRS method may yield estimates at variance with those obtained from a method that incorporates the structural change variable. Hence the structural effect calculated as a residual by the RRS method contains more than the effect of structural change (including the joint effects of other variables.). Sun (1998) has used a complete decomposition model where residuals are decomposed by the jointly created and equally distributed rule and compared the results with the general decomposition modeling. In the analysis we use the "Sun method" (see the decompositions equation) of total decomposition analysis. Bhattacharya and Paul (2001) used the total decomposition approach on energy consumption and energy intensity at sectoral level (agriculture, industry, transport, others). They have shown that the intensity effect contributes significantly to energy conservation. However, they have not disaggregated the analysis at industry level and for $\mathrm{CO}_{2}$ emissions and $\mathrm{CO}_{2}$ intensity. But in this study we 
decompose the energy consumption, energy intensity, $\mathrm{CO}_{2}$ emission and $\mathrm{CO}_{2}$ intensity at industry level over the years.

The paper follows the bottom-up approach to aggregate the energy consumption, intensity, and emissions from micro level data to macro level (more details in data section). That means the data represented in this paper are taken from demand side consumption instead of the supply side. In this study, we first analyze the energy consumption of the Indian industry and assess the increases in energy use that come with growth in output, and the environmental impacts that accompany the increase in fuel consumption. This information has been used to develop detailed energy as well as carbon intensity indicators for the most energy-intensive industries, viz., iron and steel, aluminum, copper, textile, pulp and paper, cement, and fertilizer for the years 1992--2002. Through the use of these indicators, the governments may be able to identify which industries need to be targeted for improving energy efficiency levels. The trends in carbon intensity, and the major factors that affect it (structural and economic changes), can provide climate change policy-makers with the information needed to set $\mathrm{CO}_{2}$ targets for various industries, as well as design appropriate $\mathrm{CO}_{2}$ abatement strategies. Hence, these serve not just as monitoring tools, but also as a basis for energy efficiency policies and regulations aimed at achieving greater energy conservation. As a result, these indicators, particularly cross-country comparisons of them, are increasingly being touted as very useful and necessary instruments for policy-making. Finally, measuring changes in energy intensity can provide policy-makers with the information needed to design appropriate energy conservation strategies.

\section{METHODOLOGY OF THE STUDY}

The approach adopted in this study is to estimate and evaluate economic energy intensity indicators using decomposition analysis at industry level. The analysis utilizes an empirical method, as explained in the literature review, to examine the factors (structural, activity or technological changes) that play a significant role in reducing the energy consumption and intensity with respect to the output value. The concept of industrial energy intensity denotes the amount of energy required to produce one unit of output. Comparisons of energy intensities - among industry or countries or against "best practices" benchmark - can indicate opportunities for improvements in energy and process efficiencies. Two basic 
approaches are used to express industrial energy intensity - per unit of physical product and per unit of economic output. When output is measured in physical units, an estimate of physical energy intensity is obtained (e.g., PJ/tonne). Economic energy intensity, on the other hand, is calculated using monetary value of output measures (e.g., PJ/Rs.billion). However, it is not possible to develop an aggregate measure of energy intensity when numerous outputs/services are produced by various categories of industries. Even if the output produced by a sub-sector is the same (like tonnes, for example), the energy-consumption process to obtain that output is very different. Hence, for the present study we used economic output indicator to measure the intensity.

To develop economic intensity indicators, energy consumption and physical production data for various categories of industries are obtained for the period 1992--2002. All the data have been collected at firm and specific energy consumption level. The data have been collected from secondary sources - Center for Monitoring Indian Economy (CMIE) (Prowess) and energy profiles published by it. Fourteen types of manufacturing industries have been selected that include: (1) chemical industries (fertilizer, inorganic chemicals, organic chemicals, pesticide, cosmetics, plastic product, polymers, tyre and tube), (2) beverages and tobacco, (3) food products, (4) machinery, (5) aluminum and aluminum products, (6) copper and copper products, (7) iron and steel, (8) mining, (9) cement, (10) other non-metallic and mineral products, (11) paper and paper products, (12) services, (13) textiles, and (14) transport equipment. The industries and sub-industries included in the analysis are determined solely by the availability and quality of data. The data have been aggregated into four types of energy carriers (i) coal (ii) electricity (iii) petroleum products and (iv) gaseous products. The firm-level total energy consumption is done by sum product of all specific energy with corresponding energy conversion value. The energy consumption data have been aggregated from firm level and then at later industry level by adding all firm energy consumption of the given industry. Similarly the $\mathrm{CO}_{2}$ emission is calculated by multiplication with emission factor. The used emission factor data is based on energy types only and we have not taken into consideration the emission arising out of process. The energy consumption data consists of the following types of energy:

- Coal is the aggregate of bagasse, coal, coal and lignite, coke, and firewood from different energy units (tones, million kcal, kg) to same unit in mega joules

- Electricity is the aggregate of electricity purchased - GWh 
- Petroleum and gaseous product s are the aggregate of fuel oil, furnace oil, High speed diesel (HSD) and light diesel oil (LDO), Low sulphur heavy stock (LSHS), lignite, and others (internal generation, petroleum coke, diesel) from different energy units (kls, tones GWh ) to same unit in mega joules

The data taken here are at micro level and are more reliable than macro level because very often the macro level data are taken from supply side of the energy of a sector and is not a true representative of the actual consumption level at firm and industry level (leakage, stocking etc).

\section{TOTAL DECOMPOSITION ANALYSIS MODEL}

The approach applied for decomposing change in total energy consumption and energy intensity in manufacturing sector in Indian industry between periods (1992-2002) is a simple total differential method. In this technique, the residual obtained is due to joint effect (combination of two and three effects) distributed equally among the output effect, intensity and structural effect. The manufacturing sector energy intensity and product mix effect are taken as major components for decomposition of the manufacturing sector change in energy intensity.

Decompositions of total energy consumption and total Carbon emission are given as:

$$
\begin{aligned}
& E_{t}=\sum_{i=1}^{m} E_{i t} \\
& E_{t}=\sum_{i=1}^{m} \frac{\sum_{j=1}^{n} E_{i j t}}{P_{i t}} \cdot \frac{P_{i t}}{\sum_{i=1}^{m} P_{i t}} \sum_{i=1}^{m} P_{i t} \\
& E_{t}=\sum_{i=1}^{m} e_{i t} \cdot \alpha_{i t} \cdot P_{t}
\end{aligned}
$$

Where

$E_{i t}=$ Energy cosumption or Carbon emission by ith industry at time $\mathrm{t}$

$P_{i t}=$ Total value of output in ith industry at time $\mathrm{t}$

$P_{t}=$ Total value of output at time $\mathrm{t}$

$e_{i t}=$ Energy intensity or Carbon intensity of ith industries at time $\mathrm{t}$

$\alpha_{i t}=$ Shares of value of output for ith industries at times $\mathrm{t}$

$\mathrm{J}$ denotes the types of energy 
The total decomposition in different factors can be given as

$$
\begin{aligned}
& \Delta E_{t}=\Delta O_{\text {effect }}+\Delta e_{\text {effect }}+\Delta S T_{\text {effect }} \\
& \Delta e_{\text {effect }, t}=\sum_{i=1}^{m} \Delta e_{i t}\left(\left(P_{t} \cdot \alpha_{i t}\right)+1 / 2\left(\Delta P_{t} \cdot \alpha_{i t}+P_{t} \cdot \Delta \alpha_{i t}\right)+1 / 3\left(\Delta P_{t} \cdot \Delta \alpha_{i t}\right)\right) \\
& \Delta O_{e f f e c t, t}=\sum_{i=1}^{m} \Delta P_{t}\left(\left(e_{i t} \cdot \alpha_{i t}\right)+1 / 2\left(\Delta e_{i t} \cdot \alpha_{i t}+e_{i t} \cdot \Delta \alpha_{i t}\right)+1 / 3\left(\Delta e_{i t} \cdot \Delta \alpha_{i t}\right)\right) \\
& \Delta S T_{\text {effect }, t}=\sum_{i=1}^{m} \Delta \alpha_{i t}\left(\left(P_{t} \cdot e_{i t}\right)+1 / 2\left(\Delta P_{t} \cdot e_{i t}+P_{t} \cdot \Delta e_{i t}\right)+1 / 3\left(\Delta P_{t} \cdot \Delta e_{i t}\right)\right)
\end{aligned}
$$

Where

$\Delta O_{\text {effect, } t}$ Change in energy consumption or Carbon emission due to output effect

$\Delta e_{\text {effect, } t}$ Change in energy consumption or Carbon emission due to energy intensity effect

$\Delta S T_{\text {effect, } t}$ Change in energy consumption or Carbon emission due to structural effect

$\Delta E_{t} \quad$ Change in total consumption

Decomposition of Energy intensity and Carbon Intensity:

$$
\begin{aligned}
& e_{t}=\sum_{i=1}^{m} \sum_{j=1}^{n} \frac{E_{i j t}}{P_{t}} \\
& e_{t}=\sum_{i=1}^{m} \frac{\sum_{j=1}^{n} E_{i j t}}{P_{i t}} \cdot \frac{P_{i t}}{\sum_{i=1}^{m} P_{i t}}=\sum_{i=1}^{m} e_{i t} \cdot \alpha_{i t}
\end{aligned}
$$

The manufacturing sector energy intensity and product mix effect are taken as major components for decomposition of the manufacturing sector change in energy intensity.

Taking total differentiation of previous intensity equation w.r.t time
$\Delta e_{\text {total }}^{t}$
$=\Delta e_{\text {TMPeffect }}^{t}$
$+\Delta e_{\text {STeffect }}^{t}$
$\Delta e_{\text {TMPeffect }}^{t}$
$=\sum_{i=1}^{m} \Delta e_{i t}\left(\alpha_{i t}+1 / 2\left(\Delta \alpha_{i t}\right)\right)$
$\Delta e^{t}$ STeffect
$=\sum_{i=1}^{m}$
$\Delta \alpha_{i t}\left(e_{i t}+1 / 2\left(\Delta e_{i t}\right)\right)$

where

$\Delta e^{t}$ TMPeffect Change due to technology management and practice effect at time $t$ 
$\begin{array}{ll}\Delta e^{t} \text { STeffect } & \text { Change due to structural effect at time t } \\ \Delta e_{\text {total }}^{t} & \text { Change in total Energy intensity at time t }\end{array}$

\section{PATTERN OF ENERGY CONSUMPTION AND OUTPUT IN INDIAN INDUSTRY}

\subsection{Energy use}

In India, between 1970--71 and 2000--01, the primary energy consumption has increased from 6,274 to $18,668 \mathrm{PJ}$, at a compound growth rate of 3.7 percent per annum (Table1). The increase in primary energy consumption is about half of commercial energy use (4.66 percent per annum compounded). Total commercial energy consumption increases steadily at about 3.65 percent per annum. The reasons for the growth of commercial energy more than the primary energy can be explained by the following factors: (i) substitution of non-commercial energy with commercial energy (ii) increase in commercial energy use due to changing life styles (Sudhakara Reddy, 2005). The share of commercial energy in the total energy consumption is increasing at the rate of 1.05 percent per annum.

Table 1: Total Primary and commercial energy consumption in India (1970-2000) (PJ)

\begin{tabular}{|l|l|l|l|l|l|}
\hline \multirow{2}{*}{ Energy use } & \multicolumn{4}{|c|}{ Year } & Annual growth \\
\cline { 2 - 6 } & $1970-71$ & $1980-81$ & $1990-91$ & $2000-01$ & rate (percent) \\
\hline Primary energy consumption & 6274 & 8884 & 13017 & 18668 & 3.70 \\
\hline Commercial energy consumption & 2488 & 3440 & 6721 & 9735 & 4.66 \\
\hline Percent Shares - commercial & 39.7 & 38.7 & 51.6 & 52.2 & 0.93 \\
\hline $\begin{array}{l}\text { Total Commercial energy } \\
\text { Consumption by industry }\end{array}$ & 1235 & 1418 & 2609 & 3596 & 3.65 \\
\hline $\begin{array}{l}\text { Industry share in total commercial } \\
\text { energy Consumption }\end{array}$ & 49.64 & 41.22 & 38.82 & 36.94 & -0.98 \\
\hline
\end{tabular}

Source:: Centre for Monitoring Indian Economy Reports

The share of commercial energy use in industry is more than any other sector followed by transport, household, agriculture and commercial sectors (Table 2). There is a significant change in the energy use among various sectors. Each sector displays an increase in energy consumption between 1960 and 2001. While household and agriculture use increased by 5.30 and 8.29 percent, respectively, industrial and transport energy consumption actually decreased by 4.25 and 3.39 percent, respectively. Even though industry is the main consumer of commercial energy, its share in the total decreased at the rate of one percent per annum. The reasons for this are changes in the per-capita consumption of goods and services, shift in the 
distribution of production of industrial goods and changes in industrial economic efficiency and energy intensity.

Table2: Sector wise energy consumption in India (PJ)

\begin{tabular}{|l|c|c|c|c|c|r|}
\hline \multirow{2}{*}{ Sector } & \multicolumn{5}{|c|}{ Year } & Annual growth \\
& \multicolumn{1}{|c|}{$1960-61$} & $1970-71$ & $1980-81$ & $1990-91$ & $2000-01$ & rate ( percent) \\
\hline Industry & $685(41.3)$ & $1235(49.6)$ & $1418(41.2)$ & $2609(38.8)$ & $3596(36.3)$ & 4.25 \\
\hline Transport & $664(40.2)$ & $701(28.2)$ & $943(27.4)$ & $1473(21.9)$ & $2501(25.2$ & 3.39 \\
\hline Household & $160(9.7)$ & $304(12.2)$ & $389(11.3)$ & $878(13.1)$ & $1248(12.6)$ & 5.30 \\
\hline Agriculture & $27(1.6)$ & $67(2.7)$ & $253(7.4)$ & $610(9.1)$ & $625(6.3)$ & 8.29 \\
\hline Other & $116(7.0)$ & $181(7.3)$ & $437(12.7)$ & $1153(17.2)$ & $1941(19.6)$ & 7.32 \\
\hline Total & 1652 & 2488 & 3440 & 6721 & 9911 & 4.59 \\
\hline
\end{tabular}

Source: CMIE, 2005

Note: Figures in parentheses represent percentages

In the industrial sector, coal has the highest share among all fuels (Table 3). Although consumption increased over the study period, coal lost fuel share to natural gas. With a compound growth rate of 15.6 percent per year, gas increased its share of total energy from 2.7 percent in 1980 to 19.3 percent in 2001. The consumption of petroleum products - which includes diesel, light fuel oil, heavy fuel oil, petroleum coke, etc., has been around 22 percent and that of electricity around 12 percent. Manufacturing sector is the largest consumer of energy in the industrial sector which includes iron and steel, pulp and paper, non-metallic minerals, non-ferrous metals, chemical and petrochemical, food and tobacco, textile and leather, machineries as well as other manufacturing industries. Although energy is used in the industrial sector to produce variety products, there are a few major sub-sectors which use a sizable share of the sector's overall energy demand. They include: chemicals and petrochemicals, iron and steel, pulp and paper and cement. In the manufacturing sector, heat production is one of the most important uses for energy.

For end uses such as heating, treating, melting and smelting, and cement calcinations, direct heat and steam are used. Other important end uses are machine drive and electrolytic processing. There are other uses such as ventilation, air-conditioning, lighting of industrial facilities and on-site transport. Variations in energy use in industrial sector result from technical and process changes that affect industrial sector activity, energy use, and emissions. Changes are made in the fuel types used by industries in response to change in 
technologies, economic situations, or environmental regulations. For the present study, we analyze 13 sub-sectors that include iron and steel, chemicals, pulp and paper, cement, etc. accounting for about 66 percent total industrial energy use in 2001.

Table 3: Utilisation of various energy carriers in Industry - PJ (1980-2001)

\begin{tabular}{|l|c|c|c|c|c|c|c|c|c|}
\hline Year & Coal & Share (\%) & Electricity & Share (\%) & $\begin{array}{l}\text { Petro. } \\
\text { Prod. }\end{array}$ & $\begin{array}{l}\text { Share } \\
(\%)\end{array}$ & $\begin{array}{l}\text { Gas } \\
(\%)\end{array}$ & Total \\
\hline $1980-81$ & 892 & 62.9 & 176 & 12.4 & 313 & 22 & 38 & 2.7 & 1419 \\
\hline $1981-82$ & 1071 & 63.2 & 195 & 11.5 & 371 & 21.9 & 58 & 3.4 & 1695 \\
\hline $1982-83$ & 1150 & 64.6 & 194 & 10.9 & 367 & 20.6 & 69 & 3.9 & 1780 \\
\hline $1983-84$ & 1224 & 65.2 & 209 & 11.2 & 65 & 3.5 & 79 & 4.2 & 1577 \\
\hline $1984-85$ & 1244 & 63.3 & 231 & 11.7 & 395 & 20.1 & 96 & 4.9 & 1966 \\
\hline $1985-86$ & 1256 & 61.4 & 246 & 12 & 412 & 20.2 & 132 & 6.5 & 2046 \\
\hline $1986-87$ & 1272 & 59.2 & 258 & 12 & 440 & 20.4 & 180 & 8.4 & 2150 \\
\hline $1987-88$ & 1338 & 60.4 & 254 & 11.5 & 430 & 19.4 & 192 & 8.7 & 2214 \\
\hline $1988-89$ & 1501 & 59.7 & 277 & 11 & 467 & 18.5 & 272 & 10.8 & 2517 \\
\hline $1989-90$ & 1484 & 57.8 & 296 & 11.5 & 454 & 17.7 & 334 & 13 & 2568 \\
\hline $1990-91$ & 1648 & 57.9 & 337 & 11.8 & 501 & 17.6 & 358 & 12.6 & 2844 \\
\hline $1991-92$ & 1767 & 58.6 & 353 & 11.7 & 519 & 17.2 & 377 & 12.5 & 3016 \\
\hline $1992-93$ & 1815 & 58.7 & 346 & 11.2 & 507 & 16.4 & 424 & 13.7 & 3091 \\
\hline $1993-94$ & 1860 & 57.6 & 371 & 11.5 & 546 & 16.9 & 452 & 14 & 3229 \\
\hline $1994-95$ & 1824 & 56.5 & 374 & 11.6 & 575 & 17.8 & 452 & 14 & 3225 \\
\hline $1995-96$ & 1862 & 55.5 & 406 & 12.1 & 634 & 18.9 & 449 & 13.4 & 3351 \\
\hline $1996-97$ & 1871 & 54.1 & 405 & 11.7 & 712 & 20.6 & 470 & 13.6 & 3458 \\
\hline $1997-98$ & 1872 & 52.9 & 407 & 11.5 & 729 & 20.6 & 531 & 15 & 3538 \\
\hline $1998-99$ & 1818 & 51.3 & 408 & 11.5 & 769 & 21.7 & 549 & 15.5 & 3544 \\
\hline $1999-00$ & 1686 & 47.9 & 405 & 11.5 & 778 & 22.1 & 651 & 18.5 & 3519 \\
\hline $2000-01$ & 1708 & 47.5 & 414 & 11.5 & 780 & 21.7 & 694 & 19.3 & 3596 \\
\hline
\end{tabular}

Source : CMIE, 2005

Table 4 shows the disaggregate consumption in total manufacturing by each category. During 1981 - 2000, total industrial consumption has increased by 4.76 percent per annum. This is largely due to increase in textiles, chemicals and paper 20, 8.5, and 6.9 percent, respectively. The largest percent increase per annum in energy consumption is in textiles, jumping 20 percent since 1992 because the industry shifted from manpower and mechanical use to energy and automation. Iron and steel, and cement show declining share in total energy consumption in the year 2002 compared to 1992 by 13 and 4 percent, respectively. Other manufacturing sector which includes services, electronic and telecommunication, construction, plastic, shipping, film, food, leather, apparel, gem and jeweler, cosmetic, etc., consumed 36 percent of total energy during the year 2002. Pulp and paper consumes large 
amounts of energy in the form of biomass fuels, namely spent pulping liquor and solid wood waste. Over the study period, shares of energy consumption in other category decreased slightly (1.1 percent between 1992 and 2002) while consumption in chemicals increased from 20 percent. Consumption in the petroleum refining industry dropped significantly during this period.

Table 4: Disaggregate consumption by various category of industries in PJ

\begin{tabular}{|c|c|c|c|c|c|c|c|c|c|c|c|c|c|}
\hline Sector & 1992 & \begin{tabular}{|c|} 
Share in \\
manufacturing \\
sector (\%)
\end{tabular} & 1993 & 1994 & 1995 & 1996 & 1997 & 1998 & 1999 & 2000 & 2001 & 2002 & $\begin{array}{c}\text { Share in } \\
\text { manufacturin } \\
\text { sector (\%) }\end{array}$ \\
\hline Aluminum & 185 & 13 & 188 & 192 & 202 & 206 & 227 & 228 & 244 & 260 & 265 & 303 & 13 \\
\hline $\begin{array}{l}\text { Beverages and } \\
\text { tobacco }\end{array}$ & 2 & 0 & 3 & 3 & 3 & 3 & 3 & 3 & 3 & 3 & 2 & 4 & \\
\hline Cement & 275 & 19 & 223 & 224 & 236 & 250 & 270 & 294 & 304 & 315 & 302 & 335 & 1 \\
\hline Chemicals & 231 & 16 & 260 & 252 & 287 & 300 & 330 & 348 & 381 & 463 & 541 & 522 & 23 \\
\hline Copper & 5 & 0 & 5 & 6 & 5 & 6 & 7 & 7 & 8 & 11 & 12 & 11 & \\
\hline Food products & 15 & 1 & 17 & 19 & 22 & 28 & 31 & 38 & 41 & 46 & 48 & 49 & \\
\hline Iron and steel & 562 & 40 & 536 & 546 & 595 & 634 & 687 & 689 & 698 & 702 & 632 & 633 & 27 \\
\hline Machinery & 1 & 0 & 1 & 2 & 2 & 2 & 2 & 3 & 3 & 3 & 3 & 3 & \\
\hline Mining & 1 & 0 & 1 & 1 & 1 & 1 & 1 & 1 & 3 & 5 & 149 & 5 & \\
\hline Other non-metals & 32 & $2 \%$ & 38 & 39 & 42 & 43 & 38 & 36 & 36 & 38 & 37 & 37 & \\
\hline Paper & 57 & 4 & 53 & 54 & 57 & 72 & 72 & 88 & 78 & 88 & 108 & 111 & \\
\hline Textiles & 47 & 3 & 65 & 55 & 65 & 73 & 76 & 125 & 141 & 245 & 251 & 292 & 13 \\
\hline $\begin{array}{l}\text { Trans. } \\
\text { equipment. }\end{array}$ & 2 & 0 & 3 & 3 & 4 & 4 & 5 & 4 & 4 & 4 & 4 & 3 & \\
\hline Total & 1414 & 100 & 1390 & 1394 & 1519 & 1622 & 1749 & 1864 & 1944 & 2181 & 2353 & 2309 & 10 \\
\hline Other industries & 1430 & & 1626 & 1697 & 1710 & 1606 & 1605 & 1594 & 1594 & 1363 & 1166 & 1287 & \\
\hline Grand total & 2844 & & 3016 & 3091 & 3229 & 3228 & 3354 & 3458 & 3538 & 3544 & 3519 & 3596 & \\
\hline
\end{tabular}

The specific composition of energy use in the industrial sector is shown in table 5. In 1992, final energy consumption was dominated by coal with $76 \%$ and declined to $55 \%$ in year 2002. The overall specific energy consumption increase in petrol, gas and electricity sectors are: from 8 to 22, 6 to 7,10 to 16\% between 1992-2002 respectively. This may impact the overall energy consumption and intensity levels even if the technology is not changed. 
Table 5: Specific Energy Consumption - sector wise in PJ (1992-2002)

\begin{tabular}{|l|r|r|r|r|r|r|r|r|r|r|}
\hline & \multicolumn{9}{|c|}{1992} & \multicolumn{5}{|c|}{2002} \\
\hline Sector & \multicolumn{1}{|c|}{ Coal } & Elect. & Gas & Petro. & Total & Coal & Elect. & Gas & Petro. & Total \\
\hline Aluminum & 166.3 & 13.0 & 0.0 & 5.3 & 184.6 & 220.0 & 37.3 & 0.0 & 45.6 & 302.9 \\
\hline $\begin{array}{l}\text { Beverage and } \\
\text { tobacco. }\end{array}$ & 1.2 & 0.3 & 0.0 & 0.3 & 1.8 & 1.9 & 1.1 & 0.2 & 0.2 & 3.5 \\
\hline Cement & 242.2 & 20.5 & 7.5 & 4.6 & 274.7 & 279.1 & 37.2 & 3.2 & 15.8 & 335.2 \\
\hline Chemicals & 58.7 & 31.2 & 73.0 & 67.9 & 230.8 & 96.9 & 70.3 & 131.4 & 223.4 & 521.9 \\
\hline Copper & 0.0 & 0.0 & 4.8 & 0.0 & 4.8 & 0.0 & 0.8 & 4.0 & 6.1 & 10.9 \\
\hline Food products & 6.0 & 3.4 & 1.2 & 4.8 & 15.3 & 7.1 & 12.9 & 3.0 & 25.8 & 48.8 \\
\hline Iron and steel & 524.7 & 18.5 & 0.1 & 18.2 & 561.5 & 556.8 & 39.4 & 2.0 & 34.9 & 633.1 \\
\hline Machinery & 0.1 & 0.5 & 0.0 & 0.6 & 1.3 & 0.3 & 1.8 & 0.0 & 0.7 & 2.9 \\
\hline Mining & 0.4 & 0.0 & 0.0 & 0.1 & 0.6 & 0.5 & 2.9 & 0.0 & 1.5 & 4.8 \\
\hline Other non-met. & 3.1 & 24.9 & 1.1 & 3.0 & 32.1 & 2.9 & 16.6 & 7.1 & 10.8 & 37.4 \\
\hline Paper & 45.1 & 9.8 & 0.2 & 1.8 & 57.0 & 96.0 & 10.3 & 1.7 & 3.3 & 111.3 \\
\hline Textiles & 23.4 & 14.6 & 0.4 & 8.8 & 47.1 & 15.8 & 133.0 & 3.6 & 140.0 & 292.4 \\
\hline Trans.equip.. & 0.0 & 0.6 & 0.2 & 1.6 & 2.4 & 0.1 & 1.5 & 0.1 & 1.7 & 3.4 \\
\hline Total & 1071.3 & 137.3 & 88.5 & 117.0 & 1414.0 & 1277.4 & 365.0 & 156.3 & 509.9 & 2308.6 \\
\hline
\end{tabular}

Source: CMIE (Prowess)

Table 6: Industry output by various categories - Rs.billion (1992-2002)

\begin{tabular}{|l|r|r|r|r|r|r|r|r|r|r|r|r|}
\hline Industry & 1992 & 1993 & 1994 & 1995 & 1996 & 1997 & 1998 & 1999 & 2000 & 2001 & 2002 & GRPA \\
\hline Aluminum & 27 & 28 & 28 & 31 & 37 & 38 & 41 & 40 & 44 & 47 & 46 & 5.5 \\
\hline Beverages and tobacco & 32 & 35 & 39 & 43 & 41 & 43 & 47 & 48 & 51 & 57 & 64 & 7.2 \\
\hline Cement & 61 & 56 & 56 & 61 & 69 & 69 & 68 & 68 & 70 & 77 & 82 & 3.0 \\
\hline Chemicals & 725 & 769 & 780 & 908 & 997 & 1175 & 1164 & 1379 & 1710 & 2001 & 1900 & 10.1 \\
\hline Copper & 13 & 13 & 15 & 14 & 18 & 21 & 20 & 25 & 33 & 38 & 34 & 10.1 \\
\hline Food pro. & 68 & 74 & 85 & 100 & 124 & 147 & 177 & 203 & 214 & 222 & 226 & 12.8 \\
\hline Iron and steel & 193 & 203 & 207 & 228 & 263 & 292 & 281 & 267 & 278 & 311 & 308 & 4.8 \\
\hline Machinery & 244 & 253 & 270 & 305 & 357 & 397 & 420 & 449 & 508 & 566 & 600 & 9.4 \\
\hline Mining & 101 & 106 & 114 & 132 & 138 & 156 & 175 & 160 & 207 & 231 & 229 & 8.5 \\
\hline Other nonmetal & 20 & 22 & 28 & 32 & 36 & 41 & 49 & 51 & 58 & 66 & 69 & 13.2 \\
\hline Paper & 28 & 30 & 32 & 34 & 40 & 40 & 44 & 41 & 43 & 54 & 57 & 7.4 \\
\hline Textiles & 135 & 141 & 161 & 187 & 221 & 245 & 266 & 265 & 284 & 298 & 268 & 7.1 \\
\hline Trans. equipment & 150 & 141 & 155 & 188 & 236 & 281 & 268 & 264 & 317 & 325 & 340 & 8.5 \\
\hline Total & 1797 & 1871 & 1970 & 2263 & 2577 & 2945 & 3020 & 3260 & 3817 & 4293 & 4223 & 8.9 \\
\hline
\end{tabular}

Note: GRPA = Average growth rate per annum

Table 6 shows the value of output in various categories of industry. The main argument for using value-added as an output measure is that it relates more closely to the productive activity of the plant. In a stable macro- and microeconomic climate, such a measurement could be safely used as an indicator of production and a valid energy intensity estimate could be derived. From 1992 to 2002, along with increase in energy use of 5.02 percent per annum compounded while, the value of output has increased from Rs.1,797 to 4,223 billions at a 
compound growth rate of 9 percent per annum. The growth rate of output is more than that of commercial energy use which means that there is an overall decrease in energy intensity in manufacturing sector. Chemical industry production increased by 10 percent p.a., while that of textiles rose by seven percent p.a A growth rate of 7.4 percent was recorded in the production of paper products. The output of cement industries rose by 3 percent p.a. The output of copper and aluminum industries advanced by 10 and 5.5 percent, respectively.

\subsection{Energy Intensity}

The first step towards identifying energy efficiency trends is to calculate overall energy intensity, a general indicator of energy end-use. Energy intensity is defined here as the amount of energy (in energy units, Joule) used to produce a unit of output (in monetary units, Rs.). Energy intensity values in Indian industries over the study period (1992-2002) are provided in Table 7.

Table 7: Energy Intensity in various categories of industries (TJ/Rs. billion)

\begin{tabular}{|l|r|r|r|r|r|r|r|r|r|r|r|r|}
\hline & & & & & & & & & & & \multicolumn{2}{l|}{ GRPA } \\
Industry & 1992 & 1993 & 1994 & 1995 & 1996 & 1997 & 1998 & 1999 & 2000 & 2001 & $2002(\%)$ \\
\hline Aluminum & 6837 & 6711 & 6843 & 6500 & 5565 & 5968 & 5571 & 6108 & 5900 & 5632 & 6585 & -0.4 \\
\hline Beverages and tobacco & 56 & 71 & 74 & 67 & 80 & 60 & 57 & 54 & 49 & 37 & 55 & -0.3 \\
\hline Cement & 4502 & 3989 & 4005 & 3870 & 3627 & 3914 & 4318 & 4464 & 4500 & 3919 & 4089 & -1.0 \\
\hline Chemicals & 318 & 338 & 323 & 316 & 301 & 281 & 299 & 276 & 271 & 270 & 275 & -1.5 \\
\hline Copper & 369 & 362 & 367 & 350 & 344 & 338 & 360 & 336 & 327 & 324 & 321 & -1.4 \\
\hline Food pro. & 225 & 223 & 222 & 221 & 222 & 213 & 216 & 204 & 213 & 217 & 216 & -0.4 \\
\hline Iron and steel & 2909 & 2638 & 2636 & 2609 & 2411 & 2352 & 2453 & 2612 & 2525 & 2033 & 2056 & -3.4 \\
\hline Machinery & 5 & 6 & 6 & 6 & 6 & 6 & 6 & 6 & 5 & 6 & 5 & -1.0 \\
\hline Mining & 6 & 6 & 5 & 6 & 6 & 6 & 5 & 20 & 24 & 646 & 21 & 13.7 \\
\hline Other nonmetals & 1605 & 1709 & 1400 & 1316 & 1197 & 915 & 741 & 706 & 657 & 558 & 542 & -10.3 \\
\hline Paper & 2036 & 1760 & 1681 & 1676 & 1793 & 1810 & 2009 & 1912 & 2042 & 1991 & 1953 & -0.4 \\
\hline Textiles & 350 & 458 & 342 & 345 & 332 & 312 & 468 & 534 & 862 & 842 & 1091 & 12.1 \\
\hline Trans. Equipment & 16 & 18 & 19 & 20 & 17 & 16 & 15 & 14 & 14 & 11 & 10 & -4.6 \\
\hline Total & 787 & 743 & 708 & 671 & 629 & 594 & 617 & 596 & 571 & 548 & 547 & -4.9 \\
\hline
\end{tabular}

Note: GRPA $=$ Growth rate per annum

The most energy-intensive industry is aluminum, the other two being iron and steel, and cement. The least energy-intensive are transport equipment and machinery. A notable feature of the comparison shown in this table is the trend towards declining energy use per unit of output, as plants in the sub-sector are modernized. The energy intensity of production of all the categories except Mining and textiles has declined between 0.4 and 10.3 allowing greatly 
expanded production of these products without a substantial increase in energy use. Taking into account variations in the quality of domestic fuels and the profitability of the commodities produced by each sub-sector, the data show that energy intensities appear to have substantial room for improvement.

\subsection{Carbon emissions}

Since energy consumption is responsible for roughly 90 percent of $\mathrm{CO}_{2}$ emissions, it is important to estimate carbon emissions and emission intensity indicators which can be used for environmental monitoring. The emissions are calculated by multiplying the energy consumption of each fuel by the fuel's emission conversion factor. Energy efficiency improvements are an important tool for mitigating greenhouse gas emissions. In this study, carbon emissions from industry are calculated for all categories of industries and have been calculated for all fuel consumed by end use sectors using the IPCC norms (Coal: 111 $\mathrm{tCO}_{2} / \mathrm{TJ}$, Petroleum Products: $77 \mathrm{tCO}_{2} / \mathrm{TJ}$, Gas: $69 \mathrm{tCO}_{2} / \mathrm{TJ}$ and Electricity: $316 \mathrm{tCO}_{2} / \mathrm{TJ}$ (assuming a conversion efficiency of $24.8 \%$ in a coal-fired thermal power plant , equivalent to the use of 0.72kg coal /KWh)) (Das and Kandpal (1997a), Das and Mehra et.al. (1993), and Mehra and Damodran (1993)). The calculation of $\mathrm{CO}_{2}$ emissions is based on only the $\mathrm{CO}_{2}$ contents in different types of fuels and are considered the process-related emissions. The data on energy consumption and carbon emissions are used to calculate intensity ratios (energy or emissions over output), which are based on monetary units and indicate general trends over time.

Table 8 shows that emissions from both steel and cement industries have grown nearly 1.18 and 1.29 times, respectively, in the ten years between 1992 and 2002, while those from copper, chemical and textile industry have more than doubled. Interestingly, textile industry has now emerged to be the leader (increased by 6.93 times between 1992and 2002) in terms of carbon emissions. Emissions from food, beverage and mining have grown even more. Of all of the industrial sub-sectors, only nonmetals show a decline. Overall, the emissions pattern shown in the table reinforces the message that emissions from the industrial sector are growing, rapidly and, as such, are important candidates for adopting energy-efficiency measures. 
Table 8: Carbon emissions (Million tones of $\mathrm{CO}_{2}$ )

\begin{tabular}{|c|c|c|c|c|c|c|c|c|c|c|}
\hline \multirow{2}{*}{$\begin{array}{l}\text { Industry } \\
\text { type }\end{array}$} & \multicolumn{5}{|c|}{1992} & \multicolumn{5}{|c|}{2002} \\
\hline & Coal & Electricity & Gas & Petrol. & Total & Coal & Electricity & Gas & Petrol. & Total \\
\hline Aluminum & 18.46 & 4.11 & 0.00 & 0.41 & 22.98 & 24.42 & 11.79 & 0.00 & 3.51 & 39.72 \\
\hline Bav. \& tab. & 0.14 & 0.09 & 0.00 & 0.02 & 0.25 & 0.21 & 0.36 & 0.02 & 0.02 & 0.60 \\
\hline Cement & 26.88 & 6.47 & 0.52 & 0.35 & 34.22 & 30.97 & 11.74 & 0.22 & 1.22 & 44.15 \\
\hline Chemical & 6.52 & 9.85 & 5.04 & 5.23 & 26.63 & 10.75 & 22.21 & 9.07 & 17.20 & 59.23 \\
\hline Copper & 0.00 & 0.01 & 0.33 & 0.00 & 0.35 & 0.00 & 0.26 & 0.27 & 0.47 & 1.00 \\
\hline Food product & 0.67 & 1.06 & 0.08 & 2.06 & 3.86 & 0.79 & 4.09 & 0.21 & 5.69 & 10.77 \\
\hline Iron \& Steel & 58.24 & 5.83 & 0.01 & 1.40 & 65.49 & 61.80 & 12.45 & 0.14 & 2.69 & 77.08 \\
\hline Machinery & 0.01 & 0.17 & 0.00 & 0.05 & 0.23 & 0.04 & 0.55 & 0.00 & 0.06 & 0.65 \\
\hline Mining & 0.05 & 0.01 & 0.00 & 0.01 & 0.07 & 0.05 & 0.90 & 0.00 & 0.12 & 1.07 \\
\hline Oth nomet. & 0.34 & 7.87 & 0.07 & 0.23 & 8.52 & 0.32 & 5.25 & 0.49 & 0.83 & 6.89 \\
\hline Paper & 5.01 & 3.10 & 0.01 & 0.14 & 8.27 & 10.66 & 3.25 & 0.12 & 0.25 & 14.28 \\
\hline Textiles & 2.59 & 4.62 & 0.03 & 0.67 & 7.91 & 1.75 & 42.03 & 0.25 & 10.78 & 54.81 \\
\hline Transport & 0.00 & 0.19 & 0.01 & 0.12 & 0.33 & 0.01 & 0.48 & 0.01 & 0.13 & 0.63 \\
\hline Total & 118.91 & 43.39 & 6.10 & 10.70 & \begin{tabular}{|l|l}
179.10 \\
\end{tabular} & 141.79 & 115.35 & $\mid 10.79$ & 42.96 & \begin{tabular}{|l|l|}
610.88 \\
\end{tabular} \\
\hline
\end{tabular}

As the industrial sector expanded during the study period, energy consumption as well as carbon emissions increased. An important observation is evident when one considers the proportion of energy use and emissions contributed by the industry. The patterns of energy use and carbon emissions from industrial energy consumption, broken down by major subsectors, are shown in Table 9. As the table shows industrial energy use and greenhouse gas emissions are concentrated in major industrial sub-sectors. During the study period, at the secondary level, economies have been substituting away from coal towards other fossil fuels with lower carbon content. Iron steel industry is the biggest $\mathrm{CO}_{2}$ emitter among the all but due the conservation measures and technical upgrading of iron and steel industry their share is dropping significantly from 36.6 to 24.8 percent between 1992 and 2002. Among others, textile and chemical industry are the biggest emitters with share increasing from 14.9 to 19.1 and 7.9 to 17.6 percentages, respectively, in total $\mathrm{CO}_{2}$ emissions by manufacturing industry between 1992 and -2002. Aluminum industry was the next with 13 percent and 23 million tonnes of $\mathrm{CO}_{2}$ and shares in more or less the same with energy use. The cement was a distant fourth at 19 percent and 34.2 million tonnes and both emission level and shares increased over year's .The drastically high and significant increase was in the share and level in textile industries which grew from 4.4 to 17.6 and 8 to 55Mt of CO2. The increase in the share and $\mathrm{CO}_{2}$ emission in textile industry is because the industry has shifted from old method of production to highly mechanized method and requires more energy and emits more $\mathrm{CO}_{2}$. 
Table 9: Changes in energy use and carbon emissions (1992-2002)

\begin{tabular}{|c|c|c|c|c|c|c|c|c|}
\hline \multirow[t]{2}{*}{ Sector } & \multicolumn{4}{|c|}{1992} & \multicolumn{4}{|c|}{2002} \\
\hline & \begin{tabular}{|l} 
Energy \\
use (PJ)
\end{tabular} & $\begin{array}{l}\text { Share of } \\
\text { industry (\%) }\end{array}$ & $\begin{array}{l}\mathrm{Co}_{2} \text { (million } \\
\text { tones) }\end{array}$ & \begin{tabular}{|l|} 
Share of \\
industry (\%)
\end{tabular} & $\begin{array}{l}\text { Energy } \\
\text { Use (PJ) }\end{array}$ & $\begin{array}{l}\text { Share of } \\
\text { industry (\%) }\end{array}$ & $\begin{array}{l}\mathrm{Co}_{2} \text { (million } \\
\text { tones) }\end{array}$ & \begin{tabular}{|l|} 
Share of \\
industry (\%)
\end{tabular} \\
\hline Aluminum & 184.6 & 13.1 & 23.0 & 12.8 & 302.9 & 13.1 & 39.7 & 12.8 \\
\hline Beverages and tobacco & 1.8 & 0.1 & 0.3 & 0.1 & 3.5 & 0.2 & 0.6 & 0.2 \\
\hline Cement & 274.6 & 19.4 & 34.2 & 19.1 & 335.3 & 14.5 & 44.1 & 14.2 \\
\hline Chemical & 230.8 & 16.3 & 26.6 & 14.9 & 521.9 & 22.6 & 59.2 & 19.1 \\
\hline Copper & 4.8 & 0.3 & 0.3 & 0.2 & 10.9 & 0.5 & 1.0 & 0.3 \\
\hline Food product & 15.3 & 1.1 & 3.9 & 2.2 & 48.8 & 2.1 & 10.8 & 3.5 \\
\hline Iron and Steel & 561.5 & 39.7 & 65.5 & 36.6 & 633.1 & 27.4 & 77.1 & 24.8 \\
\hline Machinery & 1.3 & 0.1 & 0.2 & 0.1 & 2.9 & 0.1 & 0.7 & 0.2 \\
\hline Mining & 0.6 & 0.0 & 0.1 & 0.0 & 4.8 & 0.2 & 1.1 & 0.3 \\
\hline Other nonmetals & 32.1 & 2.3 & 8.5 & 4.8 & 37.4 & 1.6 & 6.9 & 2.2 \\
\hline Paper & 57.0 & 4.0 & 8.3 & 4.6 & 111.3 & 4.8 & 14.3 & $\begin{array}{l}4.6 \\
\end{array}$ \\
\hline Textiles & 47.1 & 3.3 & 7.9 & 4.4 & 292.4 & 12.7 & 54.8 & 17.6 \\
\hline Transport & 2.4 & 0.2 & 0.3 & 0.2 & 3.4 & 0.1 & 0.6 & 0.2 \\
\hline Total & 1413.9 & 100 & 179.1 & 100 & 2308.6 & 100 & 310.9 & 100 \\
\hline
\end{tabular}

\subsection{Carbon intensity}

Table 10 provides an additional example of changing carbon intensities, this time expressed in terms of energy use per unit of industrial output (value of output at constant price 1992). Here, intensities in some sub-sectors increase substantially over the period shown, others decrease, and some others rise and fall over time. One should recall that carbon intensity per unit of economic output combines trends in energy intensity per unit of physical output with trends (or variations) in the value (or market price) of the goods produced. Extra care must therefore be taken when interpreting carbon-intensity trends expressed in economic terms, particularly when comparing results from categories of industries. 
Table 10: Carbon Dioxide Emission intensities (000Tonnes $\mathrm{CO}_{2}$ /billion's Rs. of output)

\begin{tabular}{|l|r|r|r|r|r|r|r|r|r|r|r|r|}
\hline Industry & 1992 & 1993 & 1994 & 1995 & 1996 & 1997 & 1998 & 1999 & 2000 & 2001 & 2002 GRPA \\
\hline Aluminum & 851 & 971 & 974 & 903 & 774 & 823 & 770 & 844 & 817 & 777 & 863 & 0.1 \\
\hline Beverages and tobacco & 8 & 9 & 9 & 9 & 10 & 7 & 6 & 6 & 9 & 5 & 9 & 1.8 \\
\hline Cement & 561 & 503 & 520 & 504 & 467 & 506 & 557 & 584 & 593 & 507 & 538 & -0.4 \\
\hline Chemicals & 37 & 40 & 39 & 37 & 34 & 33 & 35 & 33 & 30 & 29 & 31 & -1.6 \\
\hline Copper & 27 & 25 & 27 & 32 & 32 & 25 & 27 & 32 & 31 & 29 & 29 & 0.9 \\
\hline Food pro. & 57 & 60 & 50 & 57 & 54 & 48 & 41 & 40 & 38 & 43 & 48 & -1.7 \\
\hline Iron and steel & 339 & 309 & 312 & 309 & 288 & 282 & 285 & 300 & 294 & 244 & 250 & -3.0 \\
\hline Machinery & 1 & 1 & 1 & 1 & 1 & 1 & 1 & 1 & 1 & 1 & 1 & 1.4 \\
\hline Mining & 1 & 1 & 1 & 1 & 1 & 1 & 1 & 4 & 4 & 51 & 5 & 21.0 \\
\hline Other nonmetal & 426 & 437 & 349 & 322 & 276 & 198 & 159 & 148 & 126 & 107 & 100 & -13.5 \\
\hline Paper & 295 & 258 & 247 & 242 & 248 & 250 & 264 & 256 & 269 & 257 & 251 & -1.6 \\
\hline Textiles & 59 & 81 & 64 & 62 & 59 & 55 & 103 & 126 & 159 & 155 & 205 & 13.3 \\
\hline Trans. Equipment & 2 & 3 & 3 & 3 & 3 & 2 & 2 & 2 & 2 & 2 & 2 & -1.7 \\
\hline Total & 99.7 & 98 & 94 & 88 & 82 & 77 & 82 & 80 & 75 & 70 & 74 & -2.98 \\
\hline
\end{tabular}

Note: GRPA=Growth Rate Per annum

Table 11 provides information on energy consumption, value of output, intensities of energy and $\mathrm{CO}_{2}$ emissions between 1992 and 2002 at aggregate level in manufacturing sector. The real value of output (Rs. billion) increased by 2.35 times (from 1.797 to 4,223), while energy consumption (PJ) increased by only 1.63 times (from 1,414 to 2,309). This shows that the overall intensities of energy (PJ/Rs.billion) and $\mathrm{CO}_{2}$ have dropped from 787 to 547 (TJ/Rs billion) and 99.7 to 73.6 (000 tonne $\mathrm{CO}_{2} /$ Rs Billion), respectively. The intensities of energy and $\mathrm{CO}_{2}$ declined during the study period (1992--2002) by 240 and 26 respectively. From the table we can infer that energy requirement in year 2002 was 3,323 PJ when there is no change in the energy intensity ${ }^{1}$ of the industry and structure change ${ }^{2}$ in the industry. This figure has been obtained by multiplying the intensity in year 1992 (787 TJ/billion Rs) with the value of output in 2002 (4,223 Rs.bilion) converted in PJ. But the total energy requirements in year 2002 are only 2,309 PJ. This shows that there was increase in output without a significant increase in energy use; it may be due to structural shift or increase in the use of energy efficiency or both. The $\mathrm{CO}_{2}$ emission in year 2002 would be 420.9 million tones if there were no changes in the $\mathrm{CO}_{2}$ intensity and structural changes in the industry. This figure has been obtained by multiplying the intensity in year 1992 (99.7 $000 \mathrm{CO}_{2} /$ Rs.Billion) with the value of output in $2002(4,223)$ converted in million tones of $\mathrm{CO}_{2}$. But the total $\mathrm{CO}_{2}$ emission in the year is only 311 million tonnes of $\mathrm{CO}_{2}$.

\footnotetext{
1 Industries using efficient technologies, fuel switch and good energy management practice

${ }^{2}$ Percentage change in shares of the different industries (product mix in economy changes )Product mix in the economy
} 
This shows that we had increase output without a significant increase in energy use/ $\mathrm{CO}_{2}$ emissions. This may be due to structural shift or increase in use of energy efficiency or both.

Table 11: Energy consumption, output, energy use and $\mathrm{CO}_{2}$ intensities at aggregate level

\begin{tabular}{|r|c|c|c|c|c|}
\hline \multicolumn{2}{|c|}{ Year } & $\begin{array}{l}\text { Total } \\
\text { Consumption (PJ) }\end{array}$ & $\begin{array}{l}\mathrm{CO}_{2} \text { emissions } \\
\text { Million Tonnes }\end{array}$ & $\begin{array}{l}\text { Value of outputEnergy intensity } \\
\text { (Rs.Billion) }\end{array}$ & $\begin{array}{c}\mathrm{CO}_{2} \text { Intensity (000 t } \\
\mathrm{CO}_{2} / \text { Rs. Billion) }\end{array}$ \\
\hline 1992 & 1414 & 179 & 1797 & 787 & 99.7 \\
\hline 1993 & 1390 & 183 & 1871 & 743 & 98.1 \\
\hline 1994 & 1394 & 185 & 1970 & 708 & 94.0 \\
\hline 1995 & 1519 & 200 & 2263 & 671 & 88.5 \\
\hline 1996 & 1622 & 212 & 2577 & 629 & 82.2 \\
\hline 1997 & 1749 & 228 & 2945 & 594 & 77.3 \\
\hline 1998 & 1864 & 247 & 3020 & 617 & 81.8 \\
\hline 1999 & 1944 & 262 & 3260 & 596 & 80.3 \\
\hline 2000 & 2181 & 286 & 3817 & 571 & 74.9 \\
\hline 2001 & 2353 & 300 & 4293 & 548 & 69.9 \\
\hline 2002 & 2309 & 311 & 4223 & 547 & 73.6 \\
\hline
\end{tabular}

The total increase in $\mathrm{CO}_{2}$ emission is only $131 \mathrm{Mt}$ between 1992 and 2002. The emissions are 78.5 Mt less than the increase in $\mathrm{CO}_{2}$ emission due to only activity level effects while all the other factors remain constant over time. This means that the trend in the manufacturing sector shows improvement in $\mathrm{CO}_{2}$ emission intensity with structural changes. This decreasing trend over the years for $\mathrm{CO}_{2}$ intensity is noted for all industries except aluminum, cement, machinery and textiles.

\section{DECOMPOSITION OF TOTAL ENERGY CONSUMPTION AND $\mathrm{CO}_{2}$ EMISSIONS}

Increase in energy consumption, in general, is an indicator of energy end use and of energy efficiency. However, higher energy use does not always imply less efficient use of energy. Energy consumption trends are driven by change in activity level (output level in the industry), change in energy efficiency and due to structural change in the industry (change in product mix in the industry) The impact of structure and pure intensity effects should be isolated to determine their contribution to overall energy intensity changes.

There are many methods to estimate and isolate the different effects and create the index. All the methods deal with creating the index for energy intensity by decomposing energy consumption and energy intensity. Structural changes by either the mix of activities or the mix 
of products produced by the industry in an economy affect energy intensities. In this paper, the decomposition analysis has been presented for the years 1992-2002 with a 10-year gap and the calculation was done separately for the joint activity, intensity (technology and fuel mix effects), and structural effects. While this study estimates the change in actual values over the years to understand the amount and the extent of change that has happened in the past. For the present study, we applied total differentiation decomposition analysis model since energy content varies across fuels and the substitution of one energy carrier with another affects the total energy consumption. Edwards and Pariah (Energy Policy, 1978) show that the possibilities of substitution between fossil fuels on one hand and electricity on the other are less than those among fossil fuels, but there would be certain complementarities. Hence, a more logically consistent method has been formulated for decomposing energy consumption and energy intensity in the manufacturing sector. Many a times, such changes do not reflect efficiency improvements. For example, if the production share of energy-intensive industries declines over a certain period of time, then there will be an overall decrease in energy intensity. This gives an impression that there is an improvement in energy efficiency. But the fact is that the production of energy-intensive goods has declined (a structural change), not necessarily true because, technical energy efficiency has improved. Hence it is important to find out the contribution of these changes. Decomposition methods attempt to separate changes in structural effects from changes in "pure" energy intensity for the change in energy intensity level while the same method separates all the structural effects, intensity effects and activity level effects. Such methods are useful for studying and understanding the evolution of industrial energy consumption patterns and for forecasting energy demand. They are also effective at separating and identifying the relative contributions of various factors to changes in either total energy consumption or aggregate energy-intensity. Using decomposition methods we can develop economic-intensity indicators and estimate the impact of energy efficiency which is free of structural effects.

Decomposing the change in total energy consumption between two periods of time results in three separate components or effects: (i) activity effect (change in the production level), (ii) energy intensity effect (Joule of energy consumed per Rs of value of output) which also accounts for change in fuel shift/mix in the industries, (iii) structural effect (share of value of output change across the sector with in a given time) (Ang and Lee, 1994). This implies that the changes in energy consumption during the study period can be fully explained by activity, energy intensity and structural changes. The structural effect measures changes in product mix 
in the economy, which was induced by changes in the composition of manufacturing subsectors. Economies producing large amounts of energy-intensive products like iron and steel, non-ferrous metals and cement are expected to consume more energy per unit of output than economies with structures favoring less energy-intensive industries like electronics and textile industries. In general, if the structural effect is positive, the energy intensity has increased compared with the base year. The pure intensity effect measures improvements in energy efficiency, changes in technology, fuel mix changes, efficient energy management practice as well as any other factor which is not related to activity or structure. If this effect is positive, then it implies a worsening energy efficiency scenario. A negative pure intensity effect points to improvements in energy use. The results of energy consumption decomposition analysis are presented in Tables 12 and Fig 1.

Figure 1 shows chaining and decomposition (between two consecutive years) annualized trends in pure energy consumption at the macroeconomic level. The most impressive declines in energy intensity, of about 315 and 53 percent, were realized in iron and steel, and cement, respectively. The chaining decomposition analysis in Fig. 1 shows that the intensity effect most of the times is structural effect and intensity effect was negative impact and output effect is positive impact on the total energy consumption between two consecutive years. That means the overall level of energy consumption is pulling back the structural and intensity effects and hence the total energy consumption is not an increase as it should be without these two negative factors.

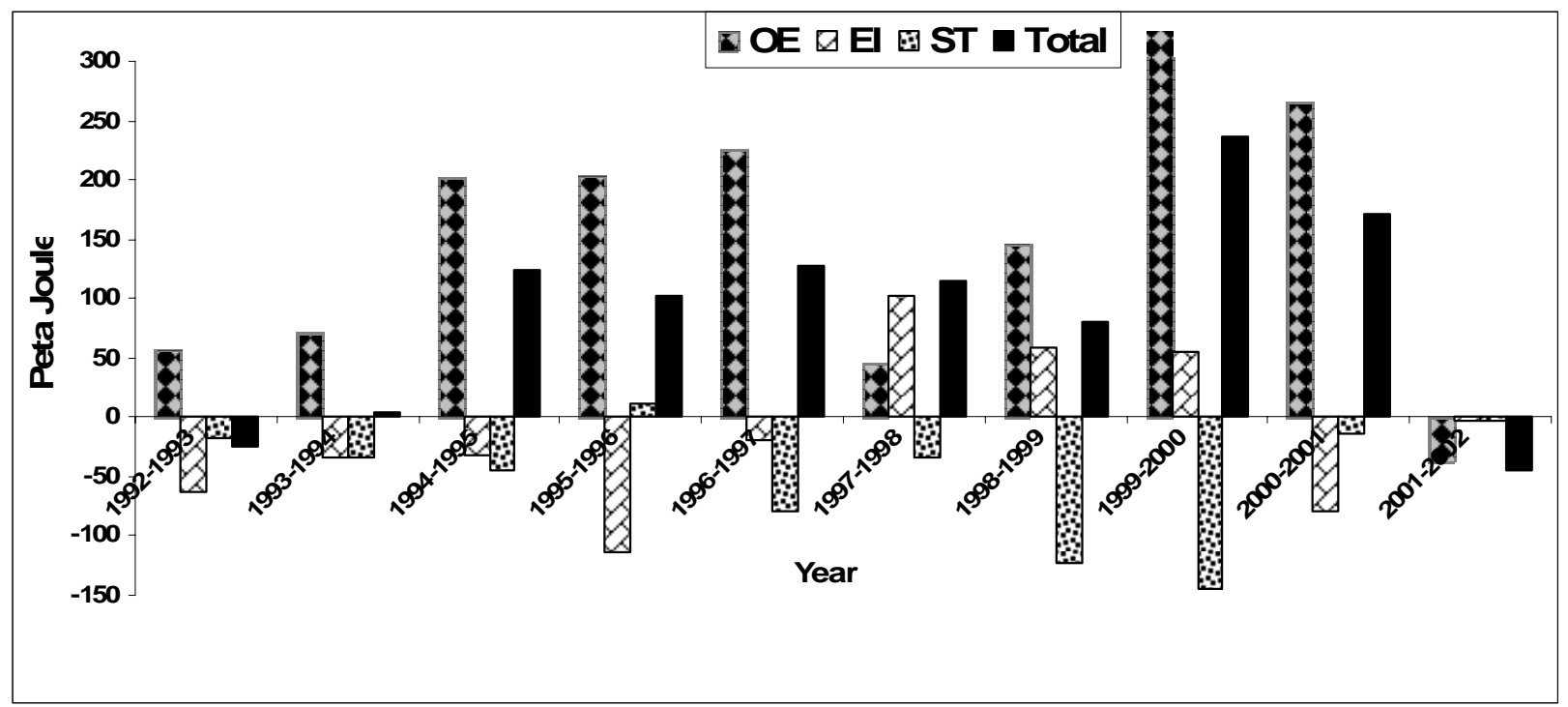

Fig 1: Decomposition of change in total energy consumption (1992-2002) 
Energy intensity and structural effects have negative impact on changes in total energy consumption. Consequently, the real energy consumption increase is only 895 PJ. This is less than the increase in energy consumption due to activity level effects while all the other factors remain constant over time. The intensity effect in all the industries, except textile and mining sector, is negative. At the aggregate level structural effect has negative impact in total energy consumption for chaining decomposition result and not chaining decomposition result except for some industries (Chemical , Copper , food product and other non metals ). This means that for the overall period of the study, 1992--2002, the structural and intensity effects are negative. This is due to shift in output shares, from high energy intensive to low intensive industries and overall gain in energy efficiency (positive energy conservation measures taken), respectively. The changes in energy consumption shares are: 180,-25 and $-55 \%$ which come from the activity, intensity and structural effect, respectively. .

Table 12: Decomposition of change in energy consumption sector wise (PJ) (1992-2002)

\begin{tabular}{|c|c|c|c|c|c|c|c|c|c|c|}
\hline \multirow[b]{2}{*}{ Industry } & \multicolumn{4}{|c|}{ Actual value } & \multicolumn{4}{|c|}{$\begin{array}{c}\text { Shares in } \\
\text { Total industry (\%) }\end{array}$} & \multicolumn{2}{|c|}{$\begin{array}{c}\text { Shares in } \\
\text { Total effect (\%) }\end{array}$} \\
\hline & $\mathrm{OE}$ & IE & SE & Total & $\mathrm{OE}$ & IE & SE & Total & $\mathrm{OE}$ & SE \\
\hline Aluminum & 211.19 & -9.63 & \begin{tabular}{|l|}
-83.26 \\
\end{tabular} & 118.30 & 13.1 & 4.4 & 416.9 & 13.2 & \begin{tabular}{|l|l|}
179 & -8 \\
\end{tabular} & -70 \\
\hline Beverages and tobacco & 2.22 & -0.08 & -0.44 & 1.70 & 0.1 & 0.0 & 0.1 & 0.2 & 131 & -26 \\
\hline Cement & 279.26 & \begin{tabular}{|l|} 
\\
\end{tabular} & \begin{tabular}{|l|l|} 
& -186.63 \\
\end{tabular} & 60.65 & 17.4 & 14.5 & 37.8 & 6.8 & \begin{tabular}{|l|l|}
460 & -53 \\
\end{tabular} & -308 \\
\hline Chemicals & 306.52 & -56.48 & 41.06 & 291.10 & 19.0 & 25.5 & \begin{tabular}{|l|l|} 
& -8.3 \\
\end{tabular} & 32.5 & \begin{tabular}{ll|}
105 & -19 \\
\end{tabular} & 14 \\
\hline Copper & 6.39 & -1.13 & 0.84 & 6.10 & 0.4 & 0.5 & \begin{tabular}{|l|}
-0.2 \\
\end{tabular} & 0.7 & \begin{tabular}{|l|l|}
105 & -18 \\
\end{tabular} & 14 \\
\hline Food pro. & 24.40 & -1.28 & 10.37 & 33.50 & 1.5 & 0.6 & -2.1 & 3.7 & 73 & 31 \\
\hline Iron and steel & 548.97 & -225.78 & -251.59 & 71.60 & 34.1 & 102.0 & 51.0 & 8.0 & $767-315$ & -351 \\
\hline Machinery & 1.71 & -0.21 & 0.10 & 1.60 & 0.1 & 0.1 & 0.0 & 0.2 & $107-13$ & 6 \\
\hline Mining & 1.82 & 2.56 & -0.09 & 4.30 & 0.1 & -1.2 & 0.0 & 0.5 & \begin{tabular}{|l|l|}
42 & 60 \\
\end{tabular} & -2 \\
\hline Other nonmetals & 34.65 & -45.06 & 15.71 & 5.30 & 2.2 & 20.4 & $4-3.2$ & 0.6 & $654-850$ & 296 \\
\hline Paper & 70.38 & -3.60 & -12.47 & 54.30 & 4.4 & 1.6 & 2.5 & 6.1 & $\begin{array}{ll}130 & -7 \\
\end{array}$ & -23 \\
\hline Textiles & 119.35 & 152.89 & -27.04 & 245.20 & 7.4 & -69.1 & 5.5 & 27.4 & \begin{tabular}{l|l|}
49 & 62 \\
\end{tabular} & -11 \\
\hline Trans. Equipment & 2.59 & -1.48 & -0.11 & 1.00 & 0.2 & 0.7 & \begin{tabular}{|l|l|}
7 & 0.0 \\
\end{tabular} & 0.1 & \begin{tabular}{|l|l|}
$259-148$ \\
\end{tabular} & -11 \\
\hline Total & 1609.45 & -221.25 & -493.55 & 894.65 & 100 & 100 & 100 & 100 & \begin{tabular}{ll|}
180 & -25 \\
\end{tabular} & -55 \\
\hline
\end{tabular}

Note: OE = Overall effect; IE = Intensity effect; SE = Structural effect

If the energy intensity and structural effect are fixed at the base year, then the quantity of energy required to maintain the increased amount of activity levels is given by only activity level effect. In a similar way, the other two effects also can be defined. As shown in Table 12 activity/output effect always influences the consumption of energy while the structural effect decreases the overall energy consumption. The intensity effect sometimes has expansion effect and other times 
depression effect; however the latter offsets the former. This means that, for the overall period of the study, due to activity effect, both the intensity and structural effects have depressed the change in total energy consumption.

The structural effect has more impact than the intensity effect (approx twice) on changes (depressing) in total energy consumption. During 1992--2002, there was a significant improvement in energy efficiency among iron and steel, chemical, aluminum, other metals, cement and paper industries. The textile industry has significant (positive) effect on increase in energy consumption by activity effect and intensity effect but the structural effect is negative. Overall, at the aggregate level, the intensity effect is negative (decreasing) because the sum of intensity effect due to iron and steel, cement, chemical, aluminum and non metals has more than positive (increasing) effect of textile and mining industries.

If the $\mathrm{CO}_{2}$ emission intensity and structural effects were fixed at the base year, then the quantity of $\mathrm{CO}_{2}$ emission would be $420.9 \mathrm{MT} \mathrm{CO}_{2}$ to maintain the increased amount of activity levels. Table 13 shows that activity/output effect always influences the $\mathrm{CO}_{2}$ emission while the structural effect and $\mathrm{CO}_{2}$ emission intensity effect decreases the overall $\mathrm{CO}_{2}$ emission level. The $\mathrm{CO}_{2}$ emission intensity effect sometimes has expansion effect and sometimes depression effect on to $\mathrm{CO}_{2}$ emission level, but the depression effect offsets the expansion effect. This means that for the overall period of the study both the intensity and structural effects have depressed the change in total energy consumption.

Table 13: Decomposition of change in $\mathrm{CO}_{2}$ emission sector wise $\mathrm{000TCO}_{2}(1992-2002)$

\begin{tabular}{|c|c|c|c|c|c|c|c|c|c|c|c|}
\hline \multirow[b]{2}{*}{ Industry } & \multicolumn{4}{|c|}{ Actual value } & \multicolumn{4}{|c|}{ \% Shares in total industry } & \multicolumn{3}{|c|}{$\%$ Shares in total effect } \\
\hline & $\mathrm{OE}$ & IE & SE & Total & OE & IE & SE & Total & $\mathrm{OE}$ & IE & SE \\
\hline Aluminum & 26942 & 472 & -10674 & 16740 & 13 & -3 & 18 & 13 & 161 & 3 & -64 \\
\hline Bev. \& tob. & 343 & 77 & -69 & 350 & 0 & 0 & 0 & 0 & 98 & 22 & -20 \\
\hline Cement & 35652 & -1745 & -23975 & 9933 & 17 & 10 & 40 & 8 & 359 & -18 & -41 \\
\hline Chemicals & 35093 & -7190 & 4697 & 32600 & 17 & 39 & -8 & 25 & 108 & -22 & 14 \\
\hline Copper & 523 & 58 & 70 & 650 & 0 & 0 & 0 & 0 & 80 & 9 & 11 \\
\hline Food pro. & 5757 & -1281 & 2435 & 6910 & 3 & 7 & -4 & 5 & 83 & -19 & 35 \\
\hline Iron \& steel & 65106 & -23552 & -29963 & 11590 & 31 & 129 & 50 & 9 & 562 & -203 & -259 \\
\hline Machinery & 342 & 59 & 19 & 420 & 0 & 0 & 0 & 0 & 81 & 14 & 5 \\
\hline Mining & 358 & 660 & -18 & 1000 & 0 & -4 & 0 & 1 & 36 & 66 & -2 \\
\hline Oth.nomet & 8417 & -13826 & 3779 & -1630 & 4 & 76 & -6 & -1 & -516 & 848 & -232 \\
\hline Paper & 9646 & -1943 & -1693 & 6010 & 5 & 11 & 3 & 5 & 161 & -32 & -28 \\
\hline Textiles & 21771 & 30091 & \begin{tabular}{|l|}
-4962 \\
\end{tabular} & 46900 & 10 & -165 & 8 & 36 & 46 & 64 & -11 \\
\hline Trans. eqp. & 403 & -85 & -18 & 300 & 0 & 0 & 0 & 0 & 134 & -28 & -6 \\
\hline Total & 210352 & -18207 & $\mid-60372$ & 131773 & 100 & 100 & 100 & 100 & 160 & -14 & -46 \\
\hline
\end{tabular}




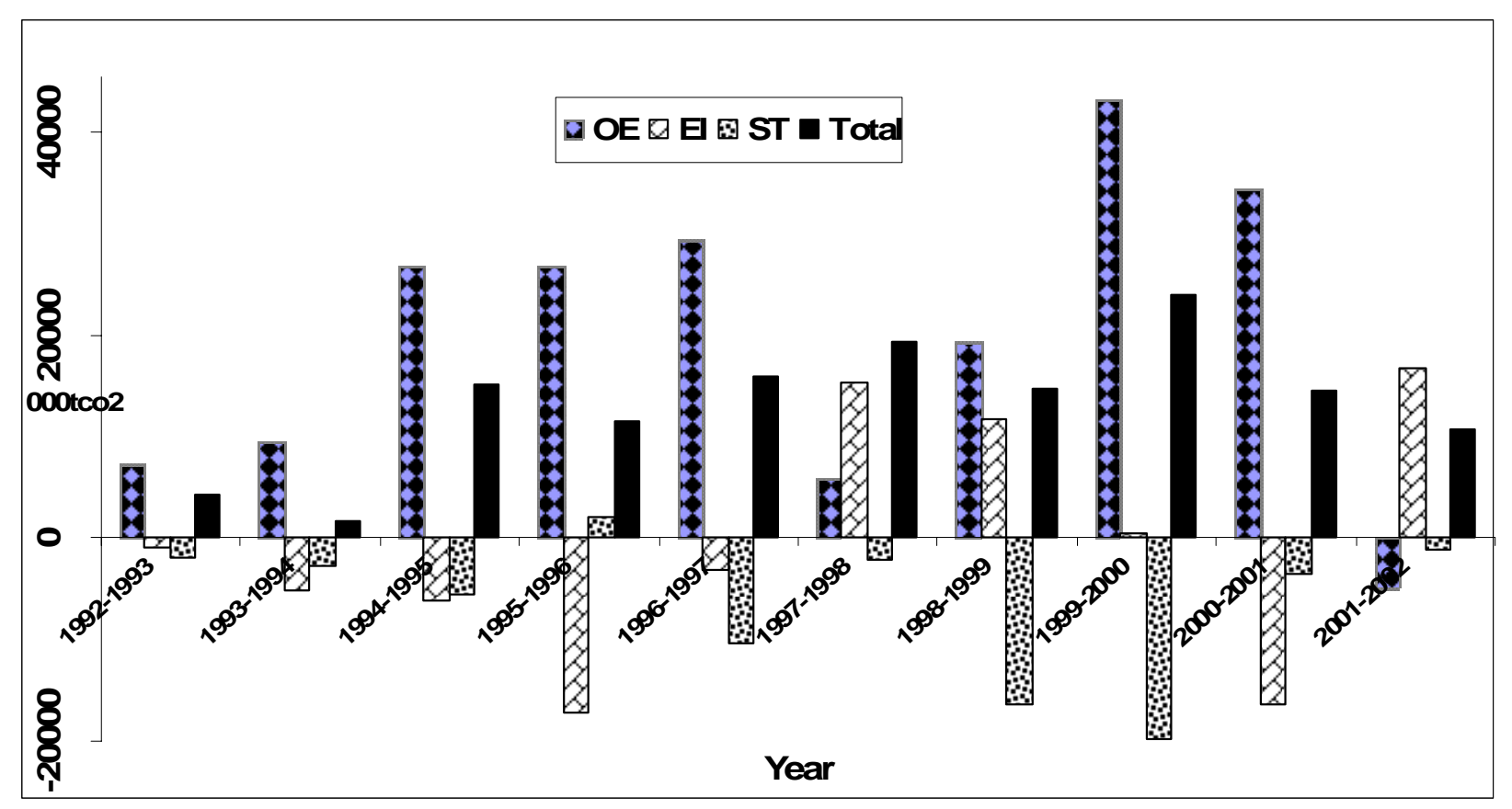

Fig 2: Decomposition of change in total emission in $\mathrm{000TCO}_{2}$ over consecutive year

The $\mathrm{CO}_{2}$ intensity effect in all the industries, except Aluminum, Bev. and Tobacco, Copper, Machinery, other non-metal and textiles are negative. But in the other industries, the intensity effect is more than that of these industries and hence overall the intensity effect has negative (decreasing) impact on the $\mathrm{CO}_{2}$ emissions and hence at the aggregate level structural effect and intensity effect negative impact in total $\mathrm{CO}_{2}$ emissions. That is for the overall period of the study, between 1992 and 2002, the structural and intensity effects are negative This is due to shift in output shares, from high energy intensive to low intensive industries and the overall gain in energy efficiency (positive energy conservation measure, fuel shift ), respectively. The changes in $\mathrm{CO}_{2}$ emission shares at aggregate level are: 160, -14 and -46 percent which come from the activity, intensity and structural effect, respectively. The decrease in energy intensity has significant impact on reducing energy consumption but the structural effect has five times more impact than the intensity effect on reducing overall energy consumption.

\section{DECOMPOSITION OF THE CHANGE OF ENERGY AND CARBON INTENSITIES}

Energy intensity, in general, is an indicator of energy end-use and thus energy efficiency. Energy intensity trends are driven by energy efficiency changes. The impact of structure should be isolated/separated form energy intensity effects to determine their contribution to overall 
energy intensity changes. The trend of energy intensities over the study period 1992--2002 is presented in Table 14. Decreasing trend in energy intensity (annual growth rate) levels, 1, 3.4 and 1.5, are noted for cement, iron and steel and chemical, respectively in Table 7. Indian industries, except mining, textile and machinery show decreasing trend of energy intensity. Figure 3 shows that energy intensity is not the same for different fuels over the study period which means that the inter-fuel substitution is taking place which can increase/decrease the energy consumption and energy intensity. As we have seen, overall energy intensity decreases over the years implying that substitution effect might have positive impact on energy conservation, energy efficiency and $\mathrm{CO}_{2}$ emission intensity.

Table 14: Decomposition of energy intensity (TJ/billion Rs 1992-2002)

\begin{tabular}{|l|c|c|c|c|c|c|c|c|}
\hline \multirow{2}{*}{ Industry } & \multicolumn{3}{|c|}{ Actual Unit } & \multicolumn{3}{c|}{ Shares in total industry (\%) } & \multicolumn{2}{c|}{ Shares in total effect (\%) } \\
\cline { 2 - 9 } & IE & SE & Total & IE & SE & Total & IE & SE \\
\hline Aluminum & -3.3 & -27.73 & -31.00 & 4.4 & 16.8 & 12.9 & 10.5 & 89.5 \\
\hline Bev. \& tob. & -0.03 & -0.15 & -0.17 & 0.0 & 0.1 & 0.1 & 14.9 & 85.1 \\
\hline Cement & -11.03 & -62.41 & -73.43 & 14.7 & 37.7 & 30.6 & 15.0 & 85.0 \\
\hline Chemicals & -18.63 & 13.78 & -4.85 & 24.9 & -8.3 & 2.0 & 384.0 & -284.0 \\
\hline Copper & -0.37 & 0.28 & -0.09 & 0.5 & -0.2 & 0.0 & 413.0 & -313.0 \\
\hline Food pro. & -0.41 & 3.46 & 3.04 & 0.6 & -2.1 & -1.3 & -13.6 & 113.6 \\
\hline Iron \& steel & -76.99 & -85.56 & -162.55 & 102.8 & 51.8 & 67.7 & 47.4 & 52.6 \\
\hline Machinery & -0.07 & 0.03 & -0.044 & 0.1 & 0.0 & 0.0 & 187.1 & -87.1 \\
\hline Mining & 0.85 & -0.03 & 0.83 & -1.1 & 0.0 & -0.3 & 103.3 & -3.3 \\
\hline Oth.nomet & -14.60 & 5.59 & -9.01 & 19.5 & -3.4 & 3.7 & 162.1 & -62.1 \\
\hline Paper & -1.21 & -4.16 & -5.36 & 1.6 & 2.5 & 2.2 & 22.5 & 77.5 \\
\hline Textiles & 51.38 & -8.40 & 42.97 & -68.6 & 5.1 & -17.9 & 119.6 & -19.6 \\
\hline Trans. eqp. & -0.49 & -0.04 & -0.53 & 0.7 & 0.0 & 0.2 & 92.7 & 7.3 \\
\hline Total & -74.9 & -165.3 & -240.2 & 100 & 100 & 100 & 31.2 & 68.8 \\
\hline
\end{tabular}

The change in energy intensity depends on the following factors: (i) energy intensity effect this factor accounts for change in fuel shift/mix and change in technology and management practices in industries over the years, and (ii) structural effect (shares of value of output change across the sector with time). Using the total differentiation model, we have arrived at the figures shown in Table 14, which shows how much each factor contributed in decreasing the overall energy intensity. The decomposition of energy intensities over the study period (1992-2002) is provided in Tables 14. Decreasing trends are noted for Iron and steel, aluminum, cement, and tobacco and beverages. The largest reductions in energy intensity have been achieved in iron and steel, cement, aluminum and paper industrial categories. 


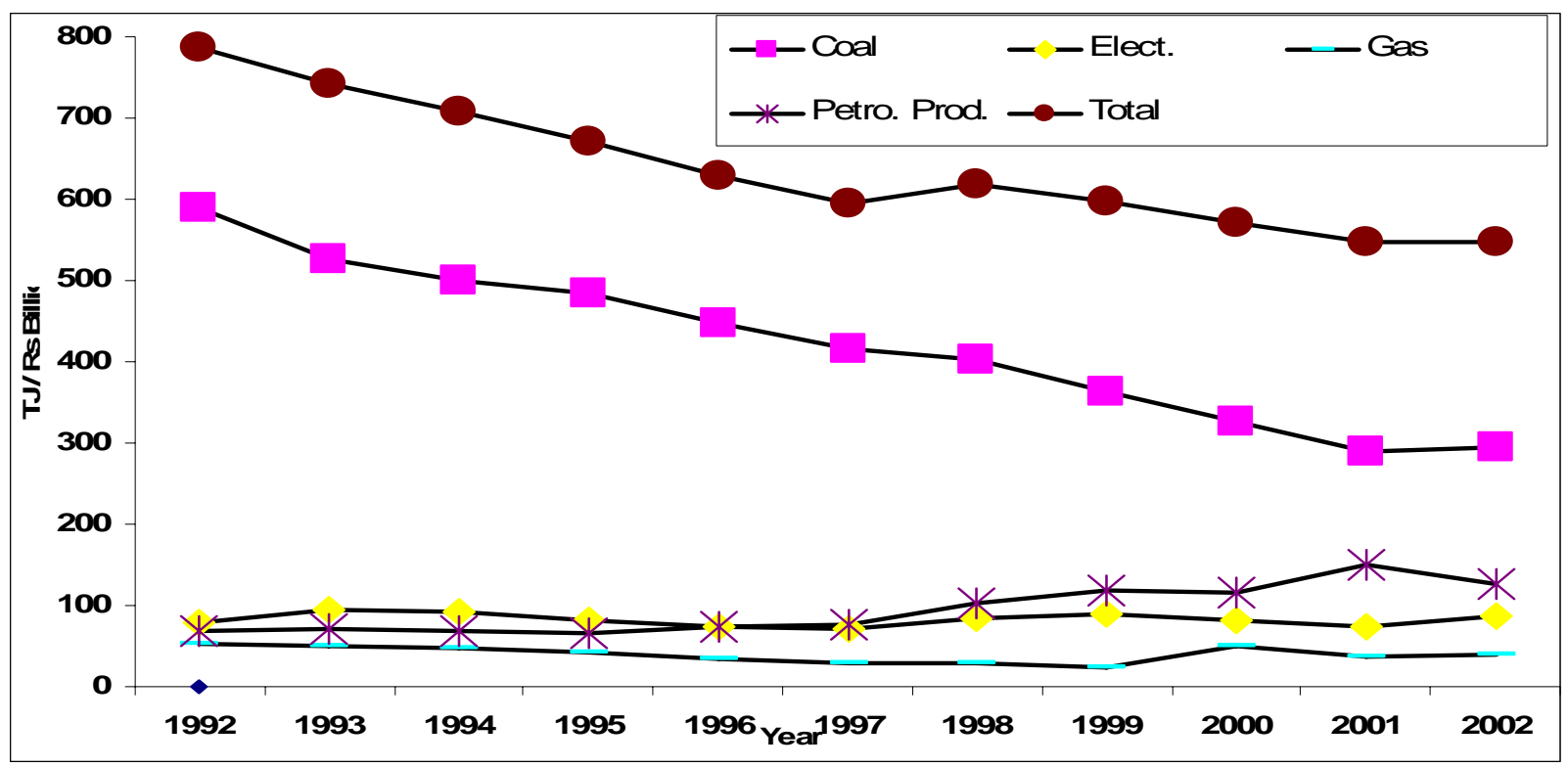

Fig 3: Specific Inter fuel substitution effect on Energy intensity in TJ/Rs Billion (1992-2002)

The overall intensity fell from 787 (TJ/billion Rs) to 547(PJ/Rs.Billion) between 1992 and 2002. The energy intensity and structural effects have negative impact on changes in total energy consumption and consequently, the real energy consumption increase is only 895 PJ. This is less than the increase in energy consumption due to activity level effects while all the other factors remain constant over time. The intensity effect in all the industries except textile and mining sector is negative. This means that the negative intensity effect dominates during the period 1992-97 and positive intensity effect during 1997--2002 periods. The structural effect has negative impact in total energy consumption during both the periods and is also negative for the entire period (1992-2002).

Between 1992 and 2002 (as shown in Table 12) the total value of output in the manufacturing sector increased by 2.35 times, while the total energy consumption increased by only 1.63 times. During the same period, the energy intensity (PJ/Rs. billion) decreased over time from 787 to 547. There is a difference between the percentage increase in total value of output and total energy consumption. This means that whatever improvements achieved in energy efficiency (or decrease in energy intensity) over time come from improvements in technologies/processes in the manufacturing sector. It is important to identify these factors and their intensity. We know that for a certain increase in economic activity, we have to increase energy consumption at the same rate. But this is possible when we are in a steady state of energy efficiency (already in the state of maximum energy efficiency, i.e., cannot increase efficiency further) and assuming other factors 
to be constant ( as we are dealing with energy intensity/efficiency at the aggregate level here). If the above case is not fulfilled, then the increase in energy consumption need not be the same as the percentage of increase at the activity level.

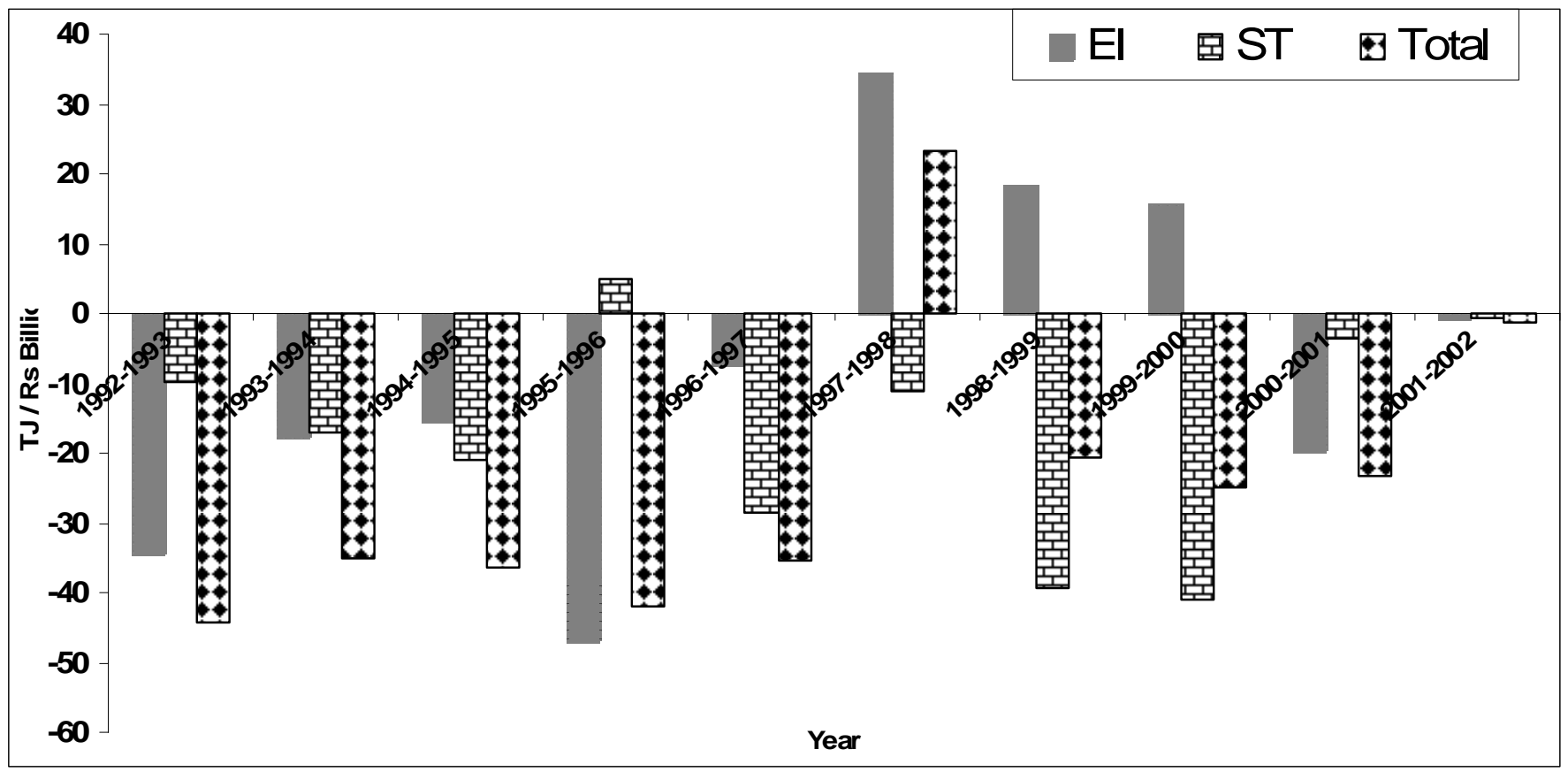

Fig 4: Decomposition for change in energy intensity (1992-2002)

In Fig. 4, energy intensity decomposition analysis is shown between two consecutive years for the period 1992 -2002. The total energy intensity is always decreasing (negative) except for the period 1997--1998. The structural effect makes a positive impact on reducing the overall energy intensity except for the period 1995--1996. For the entire study period, structural effect (product change in the economy) makes a significant impact in reducing the overall energy intensity than the TMPE effect.

As the industrial sector expanded during the study period, energy consumption and carbon emissions increased. Energy intensity (TJ/Rs Billion) and $\mathrm{CO}_{2}$ intensity (000T CO $2 / R s$ Billion) decreased from 787 to 547, and 99.7 to 73.6 during 1992--2002. The inter-fuel substitution effect also decreases the energy intensity. The coal, gas energy intensities decrease by 55\% and $25 \%$ where as electricity and Petroleum products' intensities increase by $13 \%$ and $82 \%$ respectively . 
Table 15: Decomposition and change in $\mathrm{CO}_{2}$ intensity $\left(000 \mathrm{tCO}_{2} / \mathrm{Rs}\right.$.billion) (1992-2002)

\begin{tabular}{|l|c|c|c|c|c|c|c|c|}
\hline & \multicolumn{4}{|c|}{ Actual Unit } & \multicolumn{3}{c|}{ Shares in total industry (\%) } & \multicolumn{2}{l|}{ Shares in total effect (\%) } \\
\hline Industry & IE & SE & Total & IE & SE & Total & IE & SE \\
\hline Aluminum & 0.16 & -3.54 & -3.38 & -3 & 18 & 13 & -5 & 105 \\
\hline Beverages and tobacco & 0.03 & -0.02 & 0.00 & 0 & 0 & 0 & 870 & -770 \\
\hline Cement & -0.60 & -7.99 & -8.59 & 10 & 40 & 33 & 7 & 93 \\
\hline Chemicals & -2.37 & 1.58 & -0.79 & 39 & -8 & 3 & 299 & -199 \\
\hline Copper & 0.02 & 0.02 & 0.04 & 0 & 0 & 0 & 45 & 55 \\
\hline Food pro. & -0.42 & 0.82 & 0.40 & 7 & -4 & -2 & -103 & 203 \\
\hline Iron and steel & -8.03 & -10.16 & -18.19 & 133 & 51 & 70 & 44 & 56 \\
\hline Machinery & 0.02 & 0.01 & 0.03 & 0 & 0 & 0 & 75 & 25 \\
\hline Mining & 0.22 & -0.01 & 0.21 & -4 & 0 & -1 & 102 & -2 \\
\hline Other nonmetals & -4.48 & 1.37 & -3.11 & 74 & -7 & 12 & 144 & -44 \\
\hline Paper & -0.65 & -0.57 & -1.22 & 11 & 3 & 5 & 53 & 47 \\
\hline Textiles & 10.11 & -1.53 & 8.58 & -168 & 8 & -33 & 118 & -18 \\
\hline Trans. eqipment & -0.03 & -0.01 & -0.03 & 0 & 0 & 0 & 83 & 17 \\
\hline Total & -6.02 & -20.03 & -26.06 & 100 & 100 & 100 & 23 & 77 \\
\hline
\end{tabular}

The aggregate energy intensity during 1992--2002 across the manufacturing sector falls for all types of fuels at an aggregate level. The contribution of each factor to the changes in industry energy intensity is shown in Table 15 and Fig.4. This decrease in energy intensities is due to the contribution of the structural and intensity effects and to a minor extent to combined effect. The intensity and structural effects account for approximately the same share in the decrease in total energy intensity. During the ten-year period (1992--2002), the energy intensity decreased by $240 \mathrm{TJ} / \mathrm{Rs}$. billion (Table 15). The contribution of intensity and structural effects in this decrease are: -74.9 (31.17\% of total) and -165.3 (68.83\% of total), respectively. This means that in the overall decrease in energy intensity, a significant contribution comes from the structural effect (product mix in the economy, i.e., percent shares of different sectors in the economy change.

\section{DISCUSSION AND CONCLUSIONS}

The quest to catch up with respect to lagged economic growth and rising population in developing countries has witnessed growing demand and consumption of energy products. The rise in energy consumption brings to light two crucial national issues, the issue of foreign exchange and environment. 
An indicator of energy use is energy intensity calculated at the macroeconomic level using aggregated data from micro level . It shows how various effects, either structural or activity, help change aggregate energy intensities over a certain period of time. However, this indicator provides general information on energy consumption trends and provides insight into energy efficiency. In recent times, the policy focus has shifted to environmental implications associated with energy use. The debate on greenhouse gas emissions and their role in stimulating global climate change focuses on the efficient use of energy in various countries. The amount of energy consumed by a country that uses fossil fuels, and the efficiency of its usage are two major factors determining a country's overall level of $\mathrm{CO}_{2}$ emissions. In other words, policy-makers are becoming increasingly concerned about the environmental changes relative to economic repercussions of energy use.

The economic intensity indicators that are provided in this study are critical in terms of information they can provide to policy-makers. However, measuring the true effectiveness of a policy requires careful monitoring and comparison to pre-policy data. Complete decomposition technique has been used here to help and evaluate the relative contribution of factors that effect changes in total energy consumption, energy intensity, carbon emission and carbon intensity It helps in identifying the main components of change in energy use and carbon emission and that provides greater insights into energy efficiency levels in various sectors of the economy and understand the way the structural and other effects influence energy use. The method produces indicators of "pure” energy intensity by separating out the effects of structural change. It is a significant advantage associated with their use. The method is relatively easy to apply, and typically need data that is readily available

In general, the factors behind the changes in energy intensity are structural and intensity effects and some marginal effect due to combined effect. The increase in energy consumption is mainly due to the activity level effect which is always positive. The increase in total energy consumption and carbon emission is lower than the increase in the value of output in overall manufacturing sector. This is explained by structural and intensity changes across industries, but the significant influence is from structural change which is higher than intensity change in both the cases. This means that energy intensity/TMP alone are not responsible for comparative reduction in energy consumption and carbon emission. This argument holds good when we observe the overall energy intensity decreasing over time. Among many variables available for output (e.g. value of output, gross value added, and net value added), we have considered the 
value of output because the other factors depend on marketability to sell the product or buy the raw material which does not affect the machine efficiency. Energy intensity indicators help in designing energy policies which can be used in analyses of efficiency improvements. It is recommended that such indicators be used to get a broad idea of how energy use is changing in the economy. It can be concluded that decisions regarding the choice of an appropriate energy efficiency strategy, be it market-based or command control, be evaluated using such indicators. However, a note of caution is necessary. The role of energy intensity indicators as climate change policy tools is limited. This is due to the fact that a country's ability to reduce its energy intensity(thereby its $\mathrm{CO}_{2}$ emissions) is partly a function of its cost structure and is not reflected in these indicators.

\section{REFERENCES}

Ang, B.W. (1994), Decomposition of Industrial Energy consumption: The energy intensity Approach. Energy Economics, 16. PP.163-174.

Ang, B.W.and Lee, S.Y. (1994), Decomposition of Industrial Energy consumption: Some Methodological and Application Issues. Energy Economics 16(2). PP.83-92.

CMIE, 2004, Reports of Centre for Monitoring Indian Economy, Mumbai.

Das, A, Mehra M, and Iyer M, 1993: "Strategies to Limit the Emissions of $\mathrm{CO}_{2}$ in the Indian Coal Intensive Sectors: A Scenario Analysis”, in: Amrita N. Achanta (ed.s): The Climate Change Agenda: An Indian Perspective, Tata Energy Research Institute, New Delhi, India.

Meeta M and Damodaran M, 1993: “Anthropogenic Emissions of Greenhouse Gases in India (1989-90)”, in: Amrita N. Achanta (ed.): The Climate Change Agenda: An Indian Perspective, Tata Energy Research Institute, New Delhi, India.

Edwards R and Parikh A, Intensities of energy usage an international and intertemporal comparison , Energy Policy, 1978, 6 (1), PP 66-75

Farla, J., K. Blok, and L. Schipper. 1997. "Energy Efficiency Developments in the Pulp and Paper Industry,” Energy Policy 25 (7-9): 745-758.

Jing-wen Li,ram m. Shrestha and Wesley K.Foell, 1990, Structural change and energy use, Energy

Economics, PP.109-115

Jacques Percebois. (1979) Is the concept of energy intensity meaningful? Energy Economics. PP.148-155 
Ki-Hong Choi and B.W.Ang (2003), Decomposition of aggregate energy intensity changes in two measures: ratio and difference, Energy Economics, 25 (6) PP 615-624

Lin S.J and Chang T.C (1996), Decomposition of $\mathrm{SO}_{2}, \mathrm{NO}_{\mathrm{x}}$ and $\mathrm{CO}_{2}$ emissions from energy use of major economic sectors in Taiwan, The Energy Journal 17, PP 1-17.

Boyd, G.A., Hanson, D.A. and T. Sterner (1988), Decomposition of Changes in Energy Intensity: AComparison of the Divisia Index and Other Methods, Energy Economics, 10, PP -312.

Das, A and Kandpal T.C (1997): "Energy-Environment Implications of Cement Manufacturing in India: A Scenario Analysis”, International Journal of Energy Research, 21, PP 299-308.

K.Liaskas, G.Mavrotas, M.Mandaraka, D.Diakoulaki (2000), and Decomposition of industrial

$\mathrm{CO}_{2}$ emission - the case studies of European Union. Energy Economics, 22. PP 383-394.

Lecocq Franck, and Renaud Crasous (2003), "International Climate Regime beyond 2012: Are Quota Allocation Rules Robust to Uncertainty?” Policy Research Working Paper 3000. World

Bank, Development Research Group, Washington, D.C.

Little Green Book 2007, The World Bank, Washington D.C

Miketa, (2001) Analysis of energy intensity developments in manufacturing sectors in industrialized and developing countries. Energy policy 29, PP 769-775

Nanduri M, (1998) M, An assessment of energy intensity indicators and their role as policy making tools, Report No 232, School of resource and environmental management, Simon Fraser University.

Nooji, M., R. Kruk and D. P. Soest (2003) “International Comparisons of Domestic Energy Consumption”, Energy Economics, 25, PP 259-373.

Parikh J.K and Sudhakara Reddy B, 1996, "Demand side management plan for industrial sector of Maharashtra", Compendium on "Energy efficiency and Renewable Energy Policies and practices in developing Countries", Washington.

Reddy, M. (1998). “Energy Consumption and Economic Activity in Fiji,” Journal of Pacific Studies, 22 (1 and 2) PP 81-96.

Sudhakara Reddy B (2005), Economic and Social Dimensions of Household Energy Use: A Case Study of India, in Ortega, E. and Ulgiati, S. (Editors). Proceedings of IV Biennial International Workshop “Advances in Energy Studies”, Unicamp, Campinas, SP, Brazil. June 16-19, 2004. 
R.Bhattacharya and Shyamal Paul (2001). Sectoral changes in Consumption and intensity energy in India. Indian Economic Review.Vol.XXXVI, No.2, PP.381-392

Rose, A. and S.Casler. (1996), Input-output structural Decomposition Analysis: A Critical Appraisal. Economic System Research,8,PP.33-62.

Se-Hark Park (1992), Decomposition of industrial energy consumption, Energy Economics 13, PP 265-270

Sun, J.W. (1998), Changes in energy consumption and energy intensity: A complete decomposition model, Energy Economics, 22, PP.85-100

http://earthtrends.wri.org/pdf_library/country_profiles/cli_cou_356.pdf

http://www.eia.doe.gov/oiaf/ieo/pdf/emissions.pdf 